\title{
Microphysical and Dynamical Effects of Mixed-Phase Hydrometeors in Convective Storms Using a Bin Microphysics Model: Melting
}

\author{
KEVIN G. KACAN AND ZACHARY J. LEBO \\ Department of Atmospheric Science, University of Wyoming, Laramie, Wyoming
}

(Manuscript received 25 January 2018, in final form 17 August 2019)

\begin{abstract}
The dynamics of convective systems are inherently linked to microphysical processes through phase changes that result in warming or cooling. This is especially true of near-surface cooling via evaporation and melting of falling hydrometeors. In most numerical simulations, the melting of frozen hydrometeors (e.g., hail, graupel, snow) is computed within parameterized bulk microphysics schemes, many of which lack the ability to accurately represent mixed-phase hydrometeors (i.e., partially melted ice), which can affect hydrometeor sedimentation, melting, and evaporation of shed drops. To better understand the microphysical and dynamical effects of melting in convective storms, a bin microphysics scheme was used in the Weather Research and Forecasting Model for two idealized cases: a supercell storm and a squall line. Physically based predicted liquid fraction, instantaneous melting, and instantaneous shedding schemes were used to examine the role and importance of melting hydrometeors for these two storm modes. The results suggest that the amount of precipitation is dependent on the representation of melting. Moreover, the dynamic and thermodynamic characteristics of the simulated storms are found to differ substantially between the melting scenarios, resulting in varied storm system evolution; these differences are found to be dependent on the ambient aerosol concentration, although the differences induced by changing the representation of melting generally outweigh those of changing the aerosol loading. The results highlight the large role of melting in convective storm characteristics and suggest that further model improvements are needed in the near future.
\end{abstract}

\section{Introduction}

Convection in Earth's atmosphere represents a unique coupling between small-scale microphysical process and mesoscale dynamics (e.g., Grabowski 2003; Lynn et al. 2005; Seifert and Beheng 2006; Ivanova and Leighton 2008; Altaratz et al. 2014). Mesoscale ascent creates the conditions needed for condensation to begin via adiabatic cooling. Subsequent phase changes result in warming and cooling, which can have feedbacks on the mesoscale structure of clouds and the surrounding environment (e.g., Straka and Anderson 1993; Fan et al. 2013; Wu et al. 2013; Grabowski and Morrison 2016). Furthermore, the addition of condensed water, either in its liquid or solid form, provides mass loading, which can also impact storm dynamics (e.g., Straka and Anderson 1993; Orville et al. 1989).

Accurate modeling of convective storms plays a critical role in preparing for the damaging winds, flooding rains, large hail, and tornado hazards that can be generated

Corresponding author: Zachary J. Lebo, zlebo@uwyo.edu by deep moist convective systems. These threats can have serious ramifications on life and property. Much progress has been made in the field of numerical weather prediction (NWP) by increasing model resolution to scales below which convective parameterizations are no longer needed (i.e., approximately 4 km) (e.g., Kain et al. 2008). However, increased resolution solves only part of the problem of predicting convective systems in NWP models. Therefore, it is vital to also improve the representation of the cloud microphysics due to the aforementioned feedbacks on mesoscale dynamics (e.g., Morrison and Milbrandt 2011), as well as understand the role of various processes in the evolution of convective systems.

Several recent studies have highlighted the role of various microphysical processes and the inherent sensitivities of convective storms to these processes. For example, considerable attention has been given to the role of changes in aerosol loading on convective storm characteristics (including updraft strength, precipitation, cold pool strength, hail production, lightning generation, etc.) through both modeling studies (e.g., Khain et al. 2004; Grabowski 2006; Van den Heever et al. 2006; 
Tao et al. 2007; Lee et al. 2008; Rosenfeld et al. 2008; Fan et al. 2009; Ekman et al. 2011; Seifert et al. 2012; Seigel et al. 2013; Mansell and Ziegler 2013; Lebo and Morrison 2014) and observations (e.g., Rosenfeld and Woodley 2000; Berg et al. 2008; Koren et al. 2008, 2010; Li. et al. 2011; Yuan et al. 2011; Heiblum et al. 2012). Rain drop breakup (e.g., Morrison et al. 2012; Van Weverberg et al. 2012) and melting (e.g., Rasmussen and Heymsfield 1987b; Colle et al. 2005; Marwitz 1987; Colle et al. 2002; Chen and Cotton 1988; Braun and Houze 1995; Leary and Houze 1979; Tao et al. 1990, 1995; Phillips et al. 2007; Van Weverberg et al. 2012) have also received considerable attention in the scientific literature. More specifically, melting and subsequent drop breakup and evaporation strongly impact the thermodynamics due to enthalpy changes via phase changes. In turn, these phase changes can affect the mesoscale dynamics, namely the downdraft strength, which is dependent on sublimation, melting, and evaporation (e.g., Straka and Anderson 1993; Orville et al. 1989; Corfidi 2003). Moreover, regarding the former (i.e., aerosol loading), an additional effect is the partitioning of hydrometeors - increased aerosol loading is likely to result in more numerous smaller ice crystals, thus shifting hydrometeors toward pristine ice and snow, limiting the ice that ultimately reaches the melting level. This could impact the sensitivity to melting and is addressed in this study.

More specifically in the context of melting, Colle et al. (2005) conducted high-resolution simulations of an orographic precipitation event over the Wasatch Mountains and showed that the cooling effects of evaporation and melting increased the low-level stability of the atmosphere, which promotes a blocking flow and can ultimately enhance precipitation. Marwitz (1987) drew similar conclusions regarding the role of melting and evaporation in low-level dynamics for orographic precipitation events, and Colle et al. (2002) showed the same effect in landfalling cold fronts. Furthermore, Chen and Cotton (1988) used a bulk microphysics scheme in a $2 \mathrm{D}$ convectionpermitting model with relatively coarse resolution $(4 \mathrm{~km})$ to examine the impact of melting on midlatitude mesoscale convective systems (MCSs). However, they found that melting played only a minor role. Other earlier works highlighted the importance of melting in enhancing negative buoyancy and downward transport (e.g., Braun and Houze 1995) and as a major source of rain, especially in the stratiform region of MCSs (e.g., Leary and Houze 1979; Tao et al. 1990). Later, Tao et al. (1995) used a bulk microphysics model in a 2D framework, albeit at a higher resolution than Chen and Cotton (1988), to explore the role of melting on the development of both tropical and midlatitude squall lines, showing that an erect unicellular structure evolved in the absence of cooling due to melting as opposed to an upshear-tilted line of multiple cells; their findings suggest that model resolution is another key factor for accurately representing microphysical processes and dynamical effects/feedbacks.

Melting is a complex process that occurs over time in which ice transitions to liquid (either coating the surface or filling voids in the ice matrix), with drops being shed as the ice continues to fall (e.g., Rasmussen and Heymsfield 1987a). The time-dependent nature of the process distributes the latent energy change throughout the layer below the melting level, ${ }^{1}$ while the shedding of drops is expected to play a large role in determining the raindrop size distribution, where small changes in the rain drop size distribution can have large impacts on storm evolution (e.g., Dawson et al. 2010; Lebo and Morrison 2014; Lebo 2014). Recently, Phillips et al. (2007) introduced a melting scheme that predicts the liquid water fraction of melting hydrometeors; this scheme, based on Mitra et al. (1990), Rasmussen et al. (1984), and Rasmussen and Heymsfield (1987a), was implemented in the Hebrew University Cloud Model (HUCM) to investigate the role of melting on continental and tropical squall lines. They compared simulations with the time-dependent melting formulation and instantaneous melting, showing that large ice can fall well below the melting level before being completely converted to liquid, which was found to enhance the convective destabilization of the troposphere, especially in continental cases. The destabilization results from an increase in cooling in the case of time-dependent melting, which enhances the downdraft strength, increases horizontally vorticity, and promotes the development of new convective cells. Moreover, Phillips et al. (2007) also found a large increase in precipitation when timedependent melting was included compared to instantaneous melting in certain cases, which can be tied back to the formation of new (and stronger) convective cells in the case of time-dependent melting. Although the authors used a very detailed bin microphysics scheme that can represent the retention of liquid during the melting process and the shedding of drops of a particular size, the model domain was $2 \mathrm{D}$, which is known to suppress convection and limit vertical velocities (e.g., Wilhelmson 1974; Schlesinger 1984; Weisman et al. 1997; Phillips and Donner 2006; Morrison 2016). For example, Phillips and Donner (2006) found that updrafts can be up to $50 \%$ stronger in 3D simulations compared to 2D simulations,

\footnotetext{
${ }^{1}$ In this study, we refer to the melting level as the level at which the temperature is $0^{\circ} \mathrm{C}$; this is the level at which melting can begin and can continue through the layer below this level until reaching the ground; in reality, this level is based on the level at which the wet-bulb temperature reaches $0^{\circ} \mathrm{C}$.
} 
which has been attributed to an enhancement in the vertical perturbation pressure gradient aloft in the case of 2D simulations.

Van Weverberg et al. (2012) further highlighted the role of melting and the subsequent evaporation on cold pool dynamics and precipitation efficiency, suggesting that improved formulations of ice processes (specifically collection, deposition, and melting) with more accurate representations of the relevant physics are needed due to their roles in convective systems. However, little effort has been given to further understanding the role of melting in deep convective clouds and improve the formulation of the process. One major reason for this deficiency in the literature is that most contemporary bulk microphysics schemes due not treat melting in a physically accurate manner. There are a few exceptions to this rule for which liquid water fraction is diagnosed based on the ambient microphysical characteristics (e.g., Walko et al. 1995; Loftus et al. 2014) and just two bulk parameterizations with prognostic liquid water fraction (Ferrier 1994; Cholette et al. 2019). However, these models cannot predict the evolution of the liquid water fraction, which is a size-dependent characteristic of melting hydrometeors, in the manner that a bin microphysics model can. Thus, this study focuses on understanding how differences in the representation of melting affect simulations of convective storms.

The remainder of this study is organized as follows. Section 2 provides details on the model configuration and analysis methods. Detailed results of two cases, namely a supercell and a squall-line case, are presented in sections 3 and 4 , respectively, focusing on the sensitivity of these systems to the melting process. Section 5 summarizes the key findings.

\section{Model configuration and analysis methods}

\section{a. Bin microphysics}

The Caltech-NCAR-NOAA bin scheme (Lebo and Seinfeld 2011; Lebo et al. 2012; Xue et al. 2017), which is coupled to version 3.7.1 of the Weather Research and Forecasting (WRF) Model, is used to examine the effects of melting and shedding on convective storm system structure. The original scheme included 36 bins predicting two moments in each bin (i.e., resolving the number and mass of four hydrometeor species: liquid, pristine ice, snow, and graupel/hail); a mass-doubling bin approach is used to discretize the hydrometeor size distributions. For the simulations presented herein, we expand the number of bins to 45 , allowing for the representation of hail to sizes exceeding $10 \mathrm{~cm}$ in diameter and thus allowing for an accurate depiction of melting and shedding. The graupel/hail hydrometeors belong to a hybrid category in which small hydrometeors act like graupel and large hydrometeors act more like hail with increased density, thus a higher terminal fall speed; the importance of dense precipitating ice in convective storm dynamics has been demonstrated in prior modeling sensitivity studies (e.g., Morrison and Milbrandt 2011).

The model includes an explicit treatment of aerosol particles, which is structured using 36 mass-doubling bins, albeit only the number concentration is predicted. The aerosol particles are distributed using a lognormal function with a modal diameter of $0.1 \mu \mathrm{m}$ and a log standard deviation of 1.8. Aerosol particles are activated in cloud following Köhler theory and are regenerated upon complete evaporation of a drop such that each cloud/rain drop generates a single aerosol (e.g., Mitra et al. 1990). Because the background aerosol loading can impact hydrometeor size distributions and partitioning between particle types (i.e., pristine ice versus snow or graupel/hail), two different aerosol concentrations $\left(N_{a}\right)$, namely 100 and $500 \mathrm{~cm}^{-3}$, are applied, simulating relatively clean and polluted environments, respectively; the aerosol are distributed uniformly in the vertical.

Ice nuclei are treated diagnostically. Homogeneous and immersion freezing are parameterized following Bigg (1953) and Vali (1975), respectively. Condensation and deposition freezing follow Meyers et al. (1992), and the formulations in Hallett and Mossop (1974) and Pruppacher and Klett (1997) are used for secondary ice formation, as discussed in more detail in Lebo et al. (2012). Additional details of the model physics can be found in prior works (e.g., Tzivion et al. 1987, 1989; Reisin et al. 1996; Lebo and Seinfeld 2011; Lebo et al. 2012; Xue et al. 2017), especially the riming, collision coalescence, and aggregation formulations.

One of the key additions to the model since Lebo and Seinfeld (2011) and Lebo et al. (2012) is the inclusion of an explicit melting model for ice, snow, and graupel/hail based on Rasmussen and Heymsfield (1987a) and Phillips et al. (2007), which allows hydrometeors to retain meltwater at temperatures above $0^{\circ} \mathrm{C}$. To do so, a third prognostic variable is added for each bin in the ice, snow, and graupel/hail size distributions that tracks the fraction of a hydrometeor's mass that is retained as liquid during melting. In reality, the liquid water mass mixing ratio is used in the model because it is a conserved variable. The formulations of Rasmussen and Heymsfield (1987a) are used to prognostically evolve the meltwater fraction on melting hydrometeors and determine the critical mass of meltwater. Liquid is retained on frozen hydrometeors until a critical mass of meltwater accumulates on the surface of the melting frozen hydrometeor. Rasmussen et al. (1984) defined 
7 melting modes based on the size (or Reynolds number, $N_{\mathrm{Re}}$ ) of falling ice hydrometeors; 3 of these modes result in shedding of drops at varying rates and sizes. Phillips et al. (2007) defined 4 modes that result in shedding. However, we restrict our approach to the original 3 modes defined by Rasmussen et al. (1984).

The first mode, which is applicable to the largest hydrometeors (diameters of approximately $19-20 \mathrm{~mm}$, or Reynolds numbers, $N_{\mathrm{Re}}$, of $1.5 \times 10^{4}-1.8 \times 10^{4}$ ), results in the continuous shedding of relatively small drops (diameter of $1.5 \mathrm{~mm}$ ) such that the critical meltwater mass is retained. For the second mode, melting hydrometeors with diameters of approximately $16-19 \mathrm{~mm}$ (or $N_{\mathrm{Re}}$ of $1.0 \times 10^{4}-1.5 \times 10^{4}$ ) result in the shedding of drops with a diameter of $3 \mathrm{~mm}$. The situation for the third mode (diameters of approximately $9-16 \mathrm{~mm}$, or $N_{\mathrm{Re}}$ of $6.0 \times 10^{3}-$ $\left.1.0 \times 10^{4}\right)$ is the same except that the shed drops are larger (diameter of $4.5 \mathrm{~mm}$ ). For the latter two modes, shedding can result in meltwater mass being driven below the critical value. As in Phillips et al. (2007), shedding is limited in these cases to instances where the shed meltwater cannot exceed $50 \%$ of the critical value from Rasmussen and Heymsfield (1987a). As a result, shedding essentially ceases for hail stones between 8 and $9 \mathrm{~mm}$ in diameter, which matches the results of Rasmussen et al. (1984).

The shed meltwater for each mode is transferred to the corresponding liquid bin until a melting hydrometeor reaches a diameter in which shedding is prohibited based on the aforementioned parameterization. At this point, meltwater continues to accumulate until a hydrometeor is fully melted, when it is moved to the bin in the liquid size distribution that has the same mass upon complete melting. Following Khain et al. (2004), a melt fraction threshold of 0.99 is used to indicate complete melting of a hydrometeor. Partially melted hydrometeors that are advected back above the freezing level are assumed to immediately refreeze due to the lack of timedependent freezing in the model; this is expected to have a minimal impact on the model results owing to the limited observations of the recycling of large hydrometeors (e.g., Castellano et al. 1994; Knight et al. 1975; Nelson 1983; Dennis and Musil 1973).

This melting parameterization also feeds into other processes in the model. Once liquid begins to coat a melting frozen hydrometeor, the model treats it as liquid for certain processes (e.g., condensation/evaporation instead of deposition/sublimation). This approach is in line with the approach used for high-density hail in Rasmussen and Heymsfield (1987a), in which the liquid is unable to soak into the ice structure, thus only accumulating as a coating on the surface. Moreover, liquid water that is accreted on melting hydrometeors is added to their liquid water fraction. Melting also impacts the fall speed by modifying the drag and cross-sectional area of the falling hydrometeor. To account for this effect, the fall speed is modified using a linear combination of the fall speed calculated assuming the hydrometeor is completely frozen and the fall speed assuming it is completely melted, with the weights determined from the liquid water fraction.

In addition to the aforementioned predicted liquid fraction parameterization, two additional approaches are employed in this study: instantaneous melting and instantaneous shedding. For the former, falling solid hydrometeors are immediately transferred to the corresponding bin in the liquid size distribution upon crossing the melting level. Therefore, large graupel/hail can result in drops that are aerodynamically unstable due to their large size. According to the data presented in Kamra et al. (1991), drops with a diameter of $8 \mathrm{~mm}$ have an average lifetime of just $18.7 \mathrm{~s}$, decreasing to $5 \mathrm{~s}$ or less for drops exceeding $9 \mathrm{~mm}$ in diameter (or, a time step at most; see section $2 \mathrm{~b}$ for more details on the time step). Thus, for simplicity and based on the aerodynamic breakup results of Kamra et al. (1991), drops with a diameter of $8 \mathrm{~mm}$ or more breakup spontaneously within a single time step, forming numerous smaller, more stable drops.

For the instantaneous shedding parameterization, which is intended to mimic most bulk schemes, the meltwater produced in a given time step is immediately shed. The meltwater produced in a given time step for ice species $s\left(Q_{s, \text { melt }}\right)$ is used to determine the number of shed drops following the method applied in most bulk schemes (e.g., Morrison et al. 2009; Milbrandt and Yau 2005) (i.e., by scaling such that the mean-mass diameter in each bin does not change):

$$
N_{s, r, i}=Q_{s, \text { melt }, i} \frac{N_{s, i}}{Q_{s, i}},
$$

where $N_{s, r, i}$ is the number of drops formed for melting in bin $i$ of ice species $s, Q_{s, \text { melt }, i}$ is the meltwater formed in bin $i$ from ice species $s$, and $N_{s, i}$ and $Q_{s, i}$ are the number and mass mixing ratios of ice species $s$ bin $i$, respectively. The mass and number in each bin of ice species $s$ are reduced by $Q_{s, \text { melt }, i}$ and $N_{s, r, i}$, respectively. Then, we sum $Q_{s, \text { melt }, i}$ and $N_{s, r, i}$ over all bins $i$ to determine the total melt mass and number for ice species $s$. We use these totals to determine the mean-mass radius of those drops $\left(\overline{r_{\text {shed }}}\right)$ :

$$
\bar{r}_{\text {shed }}=\left(\frac{3}{4 \pi \rho_{l}} \frac{\sum_{i=1}^{45} Q_{s, \text { melt }, i}}{\sum_{i=1}^{45} N_{s, r, i}}\right)^{1 / 3},
$$

and add them to the corresponding bin. This approach could have been applied for each bin; however, this 

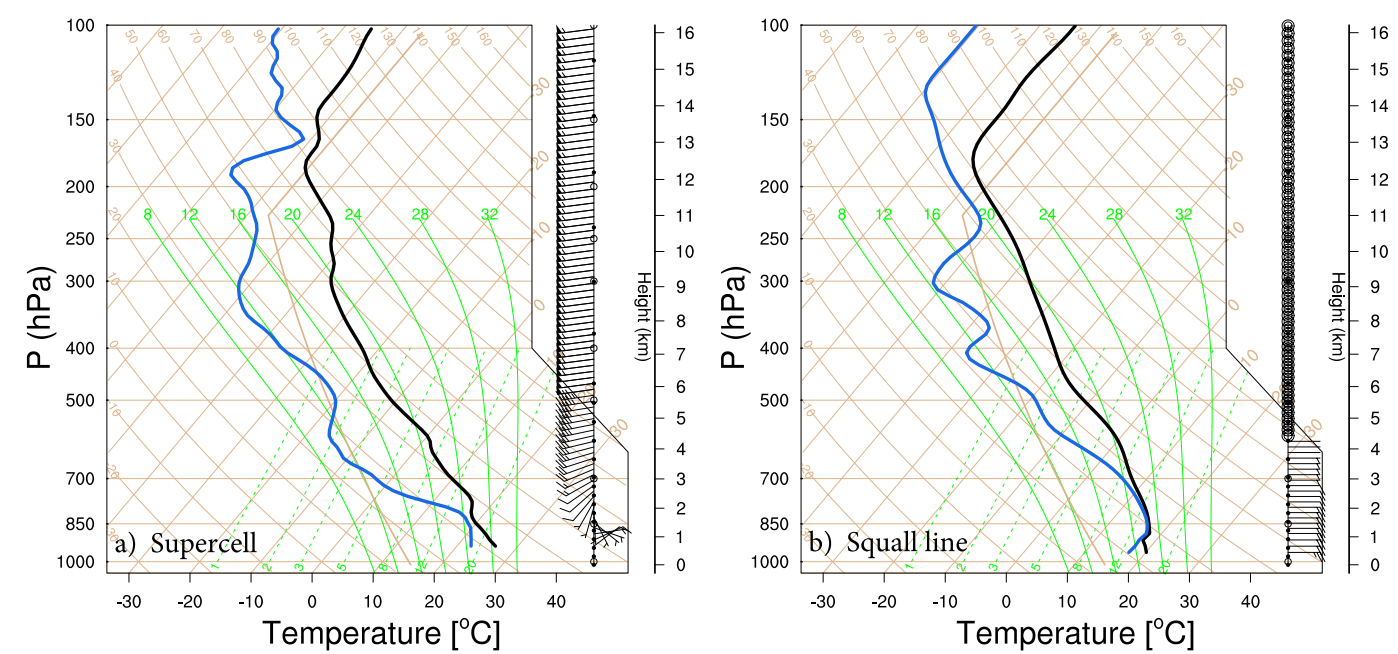

FIG. 1. Skew $T$ - $\log p$ diagrams for the initial sounding used in the (a) supercell and (b) squall-line simulations; temperature (black) and dewpoint temperature (blue) are shown in addition to wind barbs.

would result in anomalously small drops in the case of melting of small ice as well as anomalously large drops in the case of melting from ice in the largest size bins. Moreover, it is not consistent with the approach used in bulk models, where the mass and number added to the rain drop size distribution are based on the meandiameter mass of the entire distribution. The meltwater threshold is irrelevant for the instantaneous shedding simulations because by definition, frozen hydrometeors never contain liquid water on their surfaces (always shed instantly to form new drops). In line with bulk models (e.g., Morrison et al. 2009), liquid water accreted at temperatures above freezing is immediately shed assuming drops of $1 \mathrm{~mm}$ in diameter.

\section{b. Modeling cases}

\section{1) SUPERCELL}

A supercell is simulated for the three different melting parameterizations and two aerosol configurations, resulting in a suite of six simulations. The thermodynamic profile portrayed in Fig. 1a is based on the sounding applied in Orf et al. (2017), which is derived from a Rapid Update Cycle (RUC) forecast near the supercell that produced the 24 May 2011, EF5 tornado near El Reno, Oklahoma (Pazmany et al. 2013; French et al. 2015). A large amount of surfacebased convective available potential energy (SBCAPE; $4893 \mathrm{~J} \mathrm{~kg}^{-1}$ ) is present in the sounding, and the abundance of low-level moisture results in a cloud base of approximately $0.5 \mathrm{~km}$ above ground level (AGL). In the boundary layer, the environment is very moist compared to the free troposphere, which should limit evaporation and enhance melting. The wind profile is idealized and follows the quarter turn vertical shear profile of Weisman and Rotunno (2000) (hodograph length of $35 \mathrm{~m} \mathrm{~s}^{-1}$ over a depth of $6 \mathrm{~km}$ ); we elected to use the idealized wind profile as opposed to the observed for consistency with the setup of the squall-line case described below. It is important to note that the original wind profile (Orf et al. 2017) contains substantially more curvature and shear in the lowest $3 \mathrm{~km}$ than the idealized profile used here, which is expected to affect the simulated storm intensity and structure (e.g., a much more prominent hook and a more southwestnortheast orientation of the forward flank) (e.g., Tanamachi et al. 2015). However, the focus of this work is not on replicating the observed supercell but instead to examine the sensitivity of different storm modes (viz., a supercell and squall line) to melting and shedding.

Additional details regarding the model configuration are shown in Table 1. The high resolution (both horizontal and vertical resolution) of the simulations means that cumulus and planetary boundary layer parameterizations can be omitted. Positive definite advection is used in these simulations. Moreover, shortwave radiation, longwave radiation, surface layer physics, and Coriolis acceleration are neglected in these idealized simulations; these assumptions are deemed appropriate due to the short duration and strong dynamical forcing of the system. Based on the idealized initialization, all differences between simulations can be attributed to changes from internal forcings, in this case, the representation of melting and the subsequent impacts on hydrometeor loading and cooling induced by phase changes. 
TABLE 1. Domain configurations for the supercell and squall-line simulations.

\begin{tabular}{lcc}
\hline \multicolumn{1}{c}{ Description } & Supercell simulations & Squall-line simulations \\
\hline Domain extent & $151 \mathrm{~km} \times 151 \mathrm{~km} \times 21 \mathrm{~km}$ & $500 \mathrm{~km} \times 122 \mathrm{~km} \times 24 \mathrm{~km}$ \\
Horizontal grid spacing & $1 \mathrm{~km}$ & $1 \mathrm{~km}$ \\
Vertical grid spacing & $180-230 \mathrm{~m}$ (stretched; 100 levels) & $250-560 \mathrm{~m}$ (stretched; 80 levels) \\
Height of melting level & $4.1 \mathrm{~km}$ & $3.9 \mathrm{~km}$ \\
Convective initiation & $3-\mathrm{K} \theta$ perturbation bubble & Horizontal convergence $^{\mathrm{a}}$ \\
Time step & $5 \mathrm{~s}$ & Adaptive $(5-\mathrm{s}$ maximum) \\
Duration & $2 \mathrm{~h}$ & $6 \mathrm{~h}$ \\
Spinup time & $30 \mathrm{~min}$ & $1-2 \mathrm{~h}$ \\
\hline
\end{tabular}

${ }^{a}$ See Xue et al. (2017) for more details.

\section{2) SQuall LiNe}

Idealized squall-line simulations are run using the same melting and aerosol configurations as those in the supercell case with the exception of the instantaneous melting case. Simulations using instantaneous melting resulted in an unstable model, and it was thus removed from the squall-line analysis below.

The simulations represent an idealized configuration of a well-observed squall line that occurred on 20 May 2011, during the Midlatitude Continental Convective Clouds Experiment (MC3E) (e.g., Jensen et al. 2016; Wu and McFarquhar 2016; Xue et al. 2017). The squallline simulations are initialized with an environmental sounding based on observations at 1200 UTC 20 May 2011, from Morris, Oklahoma (Fig. 1), which has approximately $2200 \mathrm{~J} \mathrm{~kg}^{-1}$ of most unstable CAPE (MUCAPE). The wind profile is modified from the original sounding to ensure that a squall line forms in the simulations by employing $0.003 \mathrm{~s}^{-1}$ of unidirectional shear from the surface to a height of $4 \mathrm{~km}$. This results in a zonal (line-normal) wind speed of $-12 \mathrm{~m} \mathrm{~s}^{-1}$ at the surface, decreasing to 0 at and above $4 \mathrm{~km}$. An important characteristic of the sounding is that it is nearly saturated below $700 \mathrm{hPa}$. This differs from the supercell sounding in which the relative humidity tends to decrease below approximately $850 \mathrm{hPa}$; the different moisture profiles are expected to affect the evaporation/sublimation and melting rates in the two cases (e.g., Straka 2009). Additional details regarding the domain configuration are provided in Table 1 .

\section{Supercell results}

\section{a. Microphysical characteristics}

Vertical profiles of the horizontally averaged mass concentrations for each hydrometeor species, the liquid retained on melting ice, and the total are shown in Fig. 2. For the ice, snow, and graupel mass concentration profiles, the meltwater retained on the surfaces is not included and is instead added together and presented in
Fig. $2 \mathrm{f}$ as well as added to the rainwater concentration in Fig. $2 b$.

The cloud water concentration vertical profiles (Fig. 2a) ${ }^{2}$ are similar in that we find a peak slightly above cloud base, a rapid decrease owing to collision-coalescence converting cloud water to rain, and then a nearly uniform to slightly decreasing vertical profile with height until reaching the level of homogeneous ice nucleation (the mean height of the $-38^{\circ} \mathrm{C}$ isotherm is $9.1 \mathrm{~km}$ ). ${ }^{3}$ However, the magnitudes differ, with generally more cloud water for instantaneous melting and instantaneous shedding, hinting at the notion that there is a feedback on the dynamics of the simulation given that the melting parameterizations only have a direct effect on hydrometeors below the melting level (see section $3 \mathrm{~d}$ below). The differences in the cloud water mass concentrations between the melting parameterizations outweigh those of the different aerosol loadings except at high altitudes, where differences in heterogeneous freezing of drops becomes important as well as differences in collision-coalescence rates. This is also demonstrated by a general increase in cloud water and decrease in rainwater above the freezing level (Figs. 2a,b).

For rainwater, Fig. $2 \mathrm{~b}$ shows drastic differences among the different melting schemes. For instantaneous melting, as expected, we find a pronounced increase near $4 \mathrm{~km}$, which is indicative of the impulse of rain produced via melting below the melting level; this occurs coincident with the graupel/hail mass concentration decreasing to 0

\footnotetext{
${ }^{2}$ Here, owing to the continuous nature of the liquid size distribution, we use a radius of $50 \mu \mathrm{m}$ as the boundary between cloud and rainwater, although the results presented herein are insensitive to small changes in this choice.

${ }^{3}$ The profiles of cloud water would be unrealistic in the context of an updraft profile; however, the values shown in Fig. 2a are not conditionally averaged for any part of the system. Instead, what is shown is the average over all grid points, and can thus be directly related to the total condensate. Profiles of the conditionally averaged cloud water concentration show that the peak values occur farther above cloud base (not shown).
} 

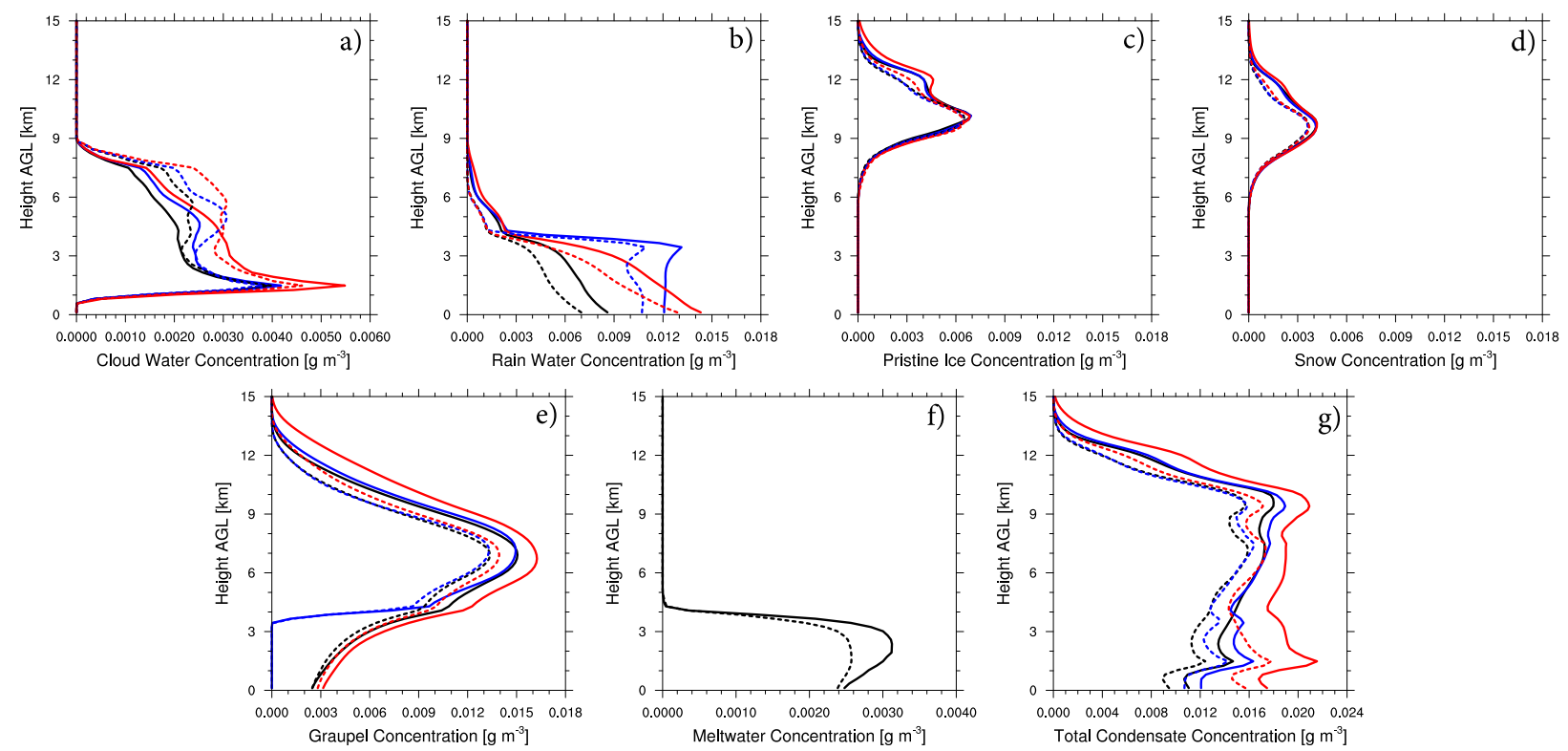

FIG. 2. Horizontally (entire domain) and temporally $(0.5-1.5 \mathrm{~h})$ averaged mass concentrations for the predicted liquid fraction (black), instantaneous melting (blue), and instantaneous shedding (red) supercell simulations with initial aerosol concentrations of $100 \mathrm{~cm}^{-3}$ (solid) and $500 \mathrm{~cm}^{-3}$ (dashed). Note that the $x$ axes in (a),(f),(g) are different to encompass the smaller and larger values of the cloud water and total mass concentration, respectively, and the meltwater in the predicted liquid fraction simulations is also included in the rainwater concentration profiles.

(Fig. 2e). Moving toward the surface, the rainwater initially decreases until approximately $3 \mathrm{~km}$, where it increases again; this increase occurs in conjunction with the peak in cloud water shown in Fig. 2a and is indicative of warm rain contributing to drops reaching sizes considerable enough to be considered rain (recall that a threshold needs to be set to define cloud and rainwater in the bin scheme). Another explanation for this decrease then increase in rainwater moving from the melting level toward the surface in the case of instantaneous melting is changes in fall speed causing mass divergence near the melting level where drops are large and thus fall fast and mass convergence at lower levels owing to the presence of smaller drops (via breakup and evaporation) and thus slower fall speeds. Moving farther toward the surface, the increase in rainwater subsides. In the downdrafts, the rainwater does in fact decrease toward the surface due to the lack of a source from warm rain (not shown).

Furthermore, the predicted liquid fraction and instant shedding schemes produce rainwater mass concentration profiles that monotonically increase toward the surface, which is due to the continuous release of liquid either at every time step in the case of the instantaneous shedding parameterization or once the sufficient conditions outlined in section 2 are met in the case of the predicted liquid fraction parameterization. However, the instantaneous shedding simulations produce more rainwater than the predicted liquid fraction simulations, which can be explained by generally higher amounts of graupel/hail and thus total condensate aloft (Figs. 2e,g). This increase in condensate can be caused by either increased areal coverage of convection or stronger updrafts, which is explored in more detail in section $3 \mathrm{~d}$.

Pristine ice and snow sublimate rapidly below approximately 10 and $9 \mathrm{~km}$, respectively (on average), with only very minuscule amounts of either species reaching the melting level; the small amount that does survive to the melting level, melts quickly (Figs. 2c,d). Moreover, given the vigorous updrafts of supercells, which can support the growth of large, dense ice, it is expected that the formation of larger and denser ice has a more prolific effect on melting than less dense and small ice, as indicated in the increase in rainwater below the melting level and the commensurate decrease in graupel/hail, which was discussed above. Near $12 \mathrm{~km}$, there is an increase in both the pristine ice and snow concentrations in the instantaneous shedding cases; this increase is indicative of a larger anvil owing to enhanced updrafts (see section $3 \mathrm{~d}$ below).

With regard to the graupel/hail mass concentrations (Fig. 2e), the three melting parameterizations result in drastically different graupel/hail concentration profiles above the melting level, where the instantaneous shedding simulations generally result in more graupel/hail regardless of the selected aerosol loading; this again indicates that the changes in the low-level environment 
induced by the different melting representations is altering the structure of the system. However, near the surface, the sensitivity to the aerosol loading nearly vanishes, and the difference in the melting scheme drives the differences in the profiles. Specifically, below the melting level, there is more graupel/hail in the instantaneous shedding case, which is at least partially because the predicted liquid fraction parameterization allows meltwater to be retained on the surface of melting ice, as shown separately in Fig. 2f. Summing the ice and liquid components of the melting graupel/hail below the melting level, one finds that the total mass simulated in the predicted liquid fraction case exceeds that of the instantaneous shedding case.

Despite the substantial differences in the individual hydrometeor species, the combined effect of these differences cancel substantially except for the instantaneous shedding simulations (Fig. $2 \mathrm{~g}$ ). The differences aloft are mainly related to the differences in graupel/hail production in the instantaneous melting case, especially with low aerosol loading (note that the enhanced cloud water concentrations in the instantaneous shedding simulations has only a minor impact on the total condensate profiles owing to the nearly order of magnitude smaller cloud water concentrations compared to the graupel/hail concentrations), especially above $4 \mathrm{~km}$, again suggesting that the changes induced by the different melting approaches have altered the structure of the storm (see section $3 \mathrm{~d}$ below for more details). Furthermore, at most levels, the differences induced by changing the melting parameterization outweigh those of changing the aerosol loading.

\section{b. Specific influence of melting on rain formation and thermodynamics}

An advantage of using a bin microphysics scheme is that details of size distributions are predicted and can be analyzed. We focus on the liquid size distributions at the surface, as shown in Fig. 3. Due to the dynamic nature of the simulated system, we cannot exclude the fact that some rain could have formed through collisioncoalescence, although we expect this contribution to be quite small and only evident in the tail at small sizes; evidence of the influence of collision-coalescence is provided by the decrease in the number of relatively small drops with increased aerosol loading. ${ }^{4}$ The rain drop size distributions exhibit two well-defined peaks

\footnotetext{
${ }^{4}$ In practice, one could implement different liquid categories based on the formation mechanism, as in Kumjian et al. (2015); however, this would result in a considerable increase in the computational cost of the simulations.
}

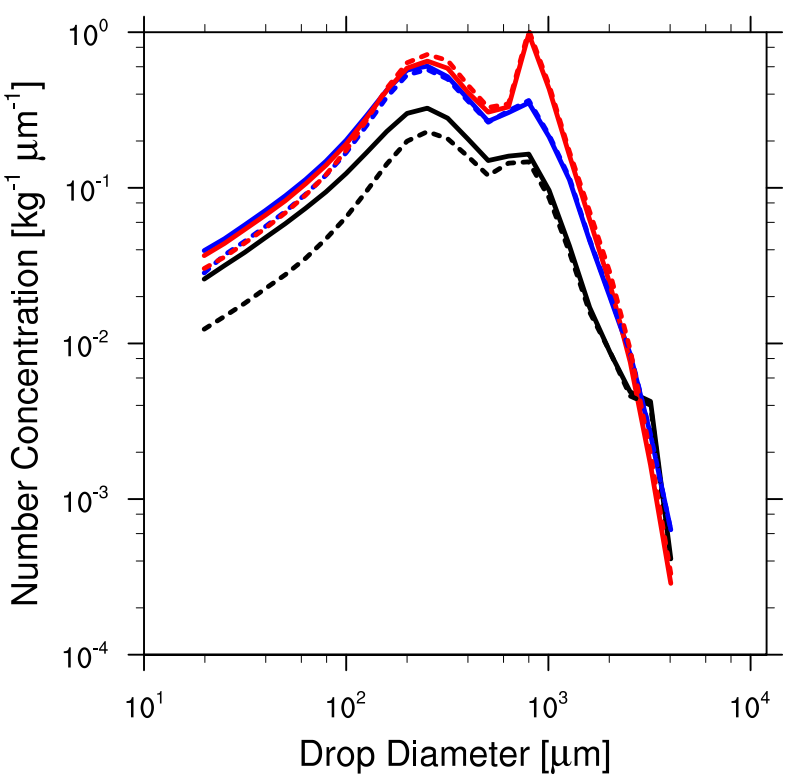

FIG. 3. Horizontally and temporally $(0.5-1.5 \mathrm{~h})$ averaged liquid drop size distributions at the lowest model level for the predicted liquid fraction (black), instantaneous melting (blue), and instantaneous shedding (red) supercell simulations with initial aerosol concentrations of $100 \mathrm{~cm}^{-3}$ (solid) and $500 \mathrm{~cm}^{-3}$ (dashed); only the model levels below the $0^{\circ} \mathrm{C}$ level and with negative $w$ are considered in the averaging.

at drop sizes of approximately 300 and $700-900 \mu \mathrm{m}$. The latter peak is persistent across all simulations, which is interesting given that the source of liquid from melting and shedding differs. There are two plausible explanations for this coinciding peak: 1 ) it is the result of melting, shedding, and evaporation in the predicted liquid fraction and instantaneous shedding cases, whereas the peak is a result of spontaneous breakup of liquid drops and subsequent evaporation, and/or 2) it results from warm-phase microphysical processes at low levels (e.g., rain self-collection and evaporation). In the instantaneous shedding simulations, this peak is much more prominent owing to the formation of drops with a diameter of $1 \mathrm{~mm}$ due to the accretion of liquid at temperatures above freezing; the slight shift toward smaller sizes is due to evaporation. Furthermore, the peak at $300 \mu \mathrm{m}$ is related to collisional breakup; simulations run without collisional breakup exhibited only the peak at 700-900 $\mu \mathrm{m}$ (not shown).

Evidence of a third peak is present in the predicted liquid fraction simulations, which is located at $3-4 \mathrm{~mm}$ in diameter (Fig. 3). This peak is the result of the second and third shedding modes described in section 2. It is important to note that the representation of this mode is only possible due to the expansion of the bin structure to 45 bins, thus providing the ability to predict graupel/hail of sizes sufficient to shed drops in these modes. 

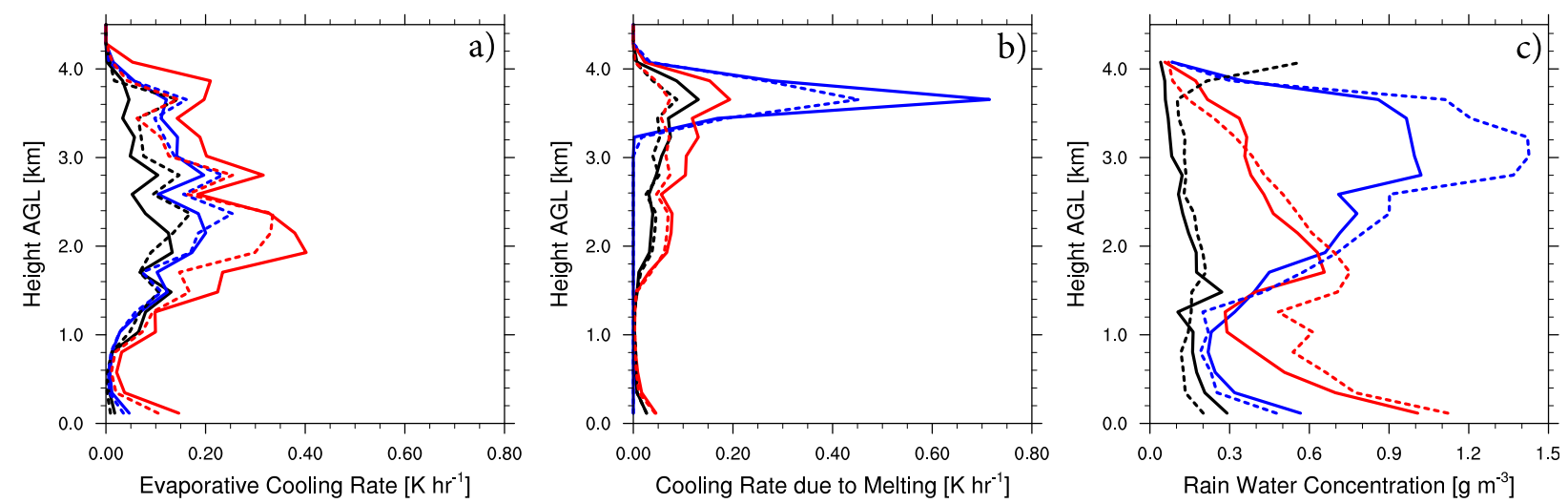

FIG. 4. (a) Horizontally averaged evaporative cooling rate, (b) cooling rate due to melting, and (c) rainwater concentration in abovefreezing regions with negative potential temperature perturbations and in downdrafts. The profiles are temporally $(0.5-1.5 \mathrm{~h})$ averaged for the predicted liquid fraction (black), instantaneous melting (blue), and instantaneous shedding (red) supercell simulations with initial aerosol concentrations of $100 \mathrm{~cm}^{-3}$ (solid) and $500 \mathrm{~cm}^{-3}$ (dashed).

In general, the surface rain drop size distributions are more sensitive to the melting parameterization than that of the aerosol loading. Higher aerosol loading results in more large drops, at least in the predicted liquid fraction and instantaneous shedding cases, and fewer small drops. This increase in the size of drops with increasing aerosol loading has been shown in several prior studies (e.g., Lebo and Morrison 2014; Lebo 2014). In the context of the different melting parameterizations, there is a general increase, regardless of size, in the number concentration of drops moving from the predicted liquid fraction simulations to instantaneous melting and then to instantaneous shedding. This order corresponds well with the rainwater concentration profiles at the surface shown in Fig. 2b. Simply stated, the instantaneous shedding simulations produce the most rain because meltwater is forced to be shed at every time step and there are dynamical feedbacks that affect the structural evolution of the simulated supercell (see section 3d).

To extend the analysis of the drop size distributions and connect to the processes and thermodynamics, we focus on the evaporative cooling rate profile, the profile of cooling due to melting, and the rainwater concentration, specifically focusing on regions with negative potential temperature perturbations and in downdrafts (Fig. 4). This conditional averaging allows us to dig deeper and focus specifically on the processes related to melting and the resulting impact on the rainwater concentration.

For instantaneous melting, large hydrometeors (i.e., radius $\geq 8 \mathrm{~mm}$ ) undergo aerodynamic breakup following melting, creating more numerous but smaller drops; collision-induced breakup can also occur. This creates a larger supply of more easily evaporated meltwater (numerous small drops) than in the predicted liquid fraction and instantaneous shedding cases by a factor of approximately 2 near the melting level (Fig. 2b), ultimately enhancing the evaporation rate (Fig. 4a); this is especially true within approximately $1-2 \mathrm{~km}$ of the melting level, where the evaporation is strongest (Fig. 4a) owing to the lower ambient relative humidities (Fig. 1). As a result, the rainwater actually decreases in this region of the domain (Fig. 2b). Further evidence of this two-step process of instantaneous melting followed by excess evaporation is presented in Fig. 4b, where we see the effects of the impulse of melting on the cooling rate. Note that the cooling rate due to melting exceeds that of evaporation in the instantaneous melting case. The increase in the rainwater concentration in the lowest $500 \mathrm{~m}$ (Fig. 4c) is largely due to flux convergence; more specifically, the evaporation rate increases close to the surface (Fig. 4a) as hydrometeors enter drier air (Fig. 1a), causing the fall speeds to decrease and thus convergence of mass. The same phenomenon is present in all simulations, being most pronounced in the instantaneous shedding simulations.

In general, the instantaneous shedding results more closely resemble those of the predicted liquid fraction simulations in terms of the thermodynamic response, albeit the cooling rates are generally higher than those of the predicted liquid fraction simulations, regardless of the aerosol loading. The increase in rainwater in the instantaneous melting simulations shown in Fig. $2 b$ in a domainwide perspective as well as in Fig. $4 \mathrm{c}$ for the cold pool is at least partially the result of increased melting (Fig. 4b). Granted, there is a commensurate increase in evaporation owing to the increase in the production of rainwater in this case (Fig. 4a); however, the rate at which rain is produced from melting and instantaneous shedding exceeds the loss from evaporation. It is 


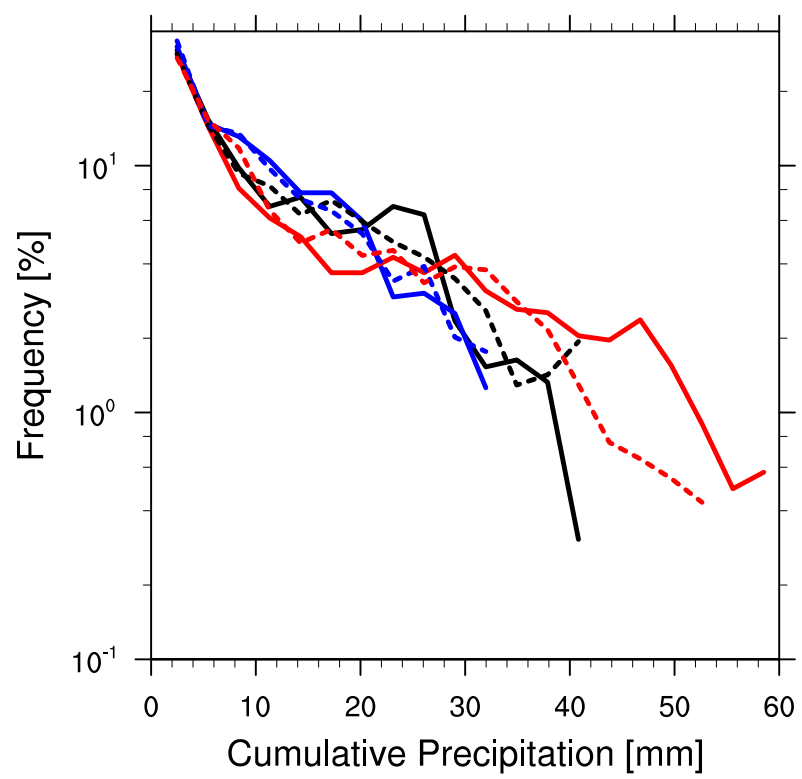

FIG. 5. PDF of cumulative precipitation (including liquid and solid precipitation) for the predicted liquid fraction (black), instantaneous melting (blue), and instantaneous shedding (red) supercell simulations; clean (solid) and polluted (dashed) conditions are presented.

important to note that the rates shown in Figs. $4 \mathrm{a}, \mathrm{b}$ are cooling rates and not the actual rates at which mass is lost or gained via evaporation or melting, respectively. Given that the enthalpy of fusion is approximately 7.5 times smaller than that of vaporization, the source of rain mass is actually greater than the loss, hence the general increase in rainwater throughout the column and moving toward the surface.

Briefly, these findings indicate that seemingly minor changes in the assumptions related to melting can have pronounced changes on the low-level thermodynamics of the simulated supercell, and these responses generally outweigh those induced by increased aerosol loading.

\section{c. Precipitation response}

The changes in the low-level thermodynamic environment and hydrometeor profiles discussed above ultimately impact the formation of precipitation and its accumulation rate at the surface. Probability distribution functions (PDFs) of the cumulative precipitation amounts are shown in Fig. 5, and the domain-averaged cumulative precipitation amounts are shown in Table 2. Regardless of the melting parameterization, there is a decrease in precipitation with increasing aerosol loading $(16 \%-39 \%$; however, in the extreme, the large difference is related to differences in storm evolution described below). Moreover, the predicted liquid fraction and instantaneous melting simulations result in similar cumulative precipitation amounts, with the instantaneous shedding simulations resulting in up to $73 \%$ more precipitation; this is largely related to regions experience cumulative precipitation amounts in excess of $40 \mathrm{~mm}$ that are not present in the simulations performed with instantaneous melting or predicted liquid fraction (Fig. 5). These differences in cumulative precipitation for the different melting parameterizations should come as no surprise given the aforementioned hydrometeor concentration profiles (i.e., Fig. 2 and section 3a).

While the total precipitation differences are largely a reflection of the condensate concentrations at the surface shown in Fig. 2, the fraction reaching the surface as solid versus liquid is more a reflection of Figs. 2b,e,f at the surface, and these fractions are illustrated in Table 2. The differences in the fraction of precipitation reaching the surface as ice are similar except for the clean instantaneous shedding case, which again is related to storm structure differences discussed in the following subsection.

\section{d. Simulated radar reflectivity, storm structure, and dynamics}

Figure 6 shows the surface kinematic and thermodynamic fields (surface wind vectors, surface convergence, and cold pool) and simulated radar reflectivity for the lowest model level at $1.25 \mathrm{~h}$. The calculation of the radar reflectivity follows that of Sarkadi et al. (2016) and Xue et al. (2017), which closely follows the work of Smith (1984) and Blahak (2007). This algorithm considers the dependence of reflectivity on the following factors: hydrometeor size, melt fraction, radar wavelength [assumed to be $10 \mathrm{~cm}$ (i.e., S-band)], temperature, and phasedependent refractivity.

For clockwise shear, as is present in the supercell initialization (see Fig. 1), the right-moving cell (rightmover) dominates, containing the mesocyclone (e.g., Davies-Jones 1984; Houze et al. 1993; Bluestein and Weisman 2000); in this case, the left-mover is

TABLE 2. Domain-averaged precipitation (liquid plus ice) at the end of the supercell simulations; fraction of precipitation falling as ice is shown in parentheses.

\begin{tabular}{lccc}
\hline \hline & Predicted liquid fraction & Instantaneous shedding & Instantaneous melting \\
\hline$N_{a}=100 \mathrm{~cm}^{-3}$ & $0.52 \mathrm{~mm}(28.4 \%)$ & $0.90 \mathrm{~mm}(40.3 \%)$ & $0.43 \mathrm{~mm}(0 \%)$ \\
$N_{a}=500 \mathrm{~cm}^{-3}$ & $0.43 \mathrm{~mm}(29.0 \%)$ & $0.55 \mathrm{~mm}(26.8 \%)$ & $0.36 \mathrm{~mm}(0 \%)$ \\
\hline
\end{tabular}



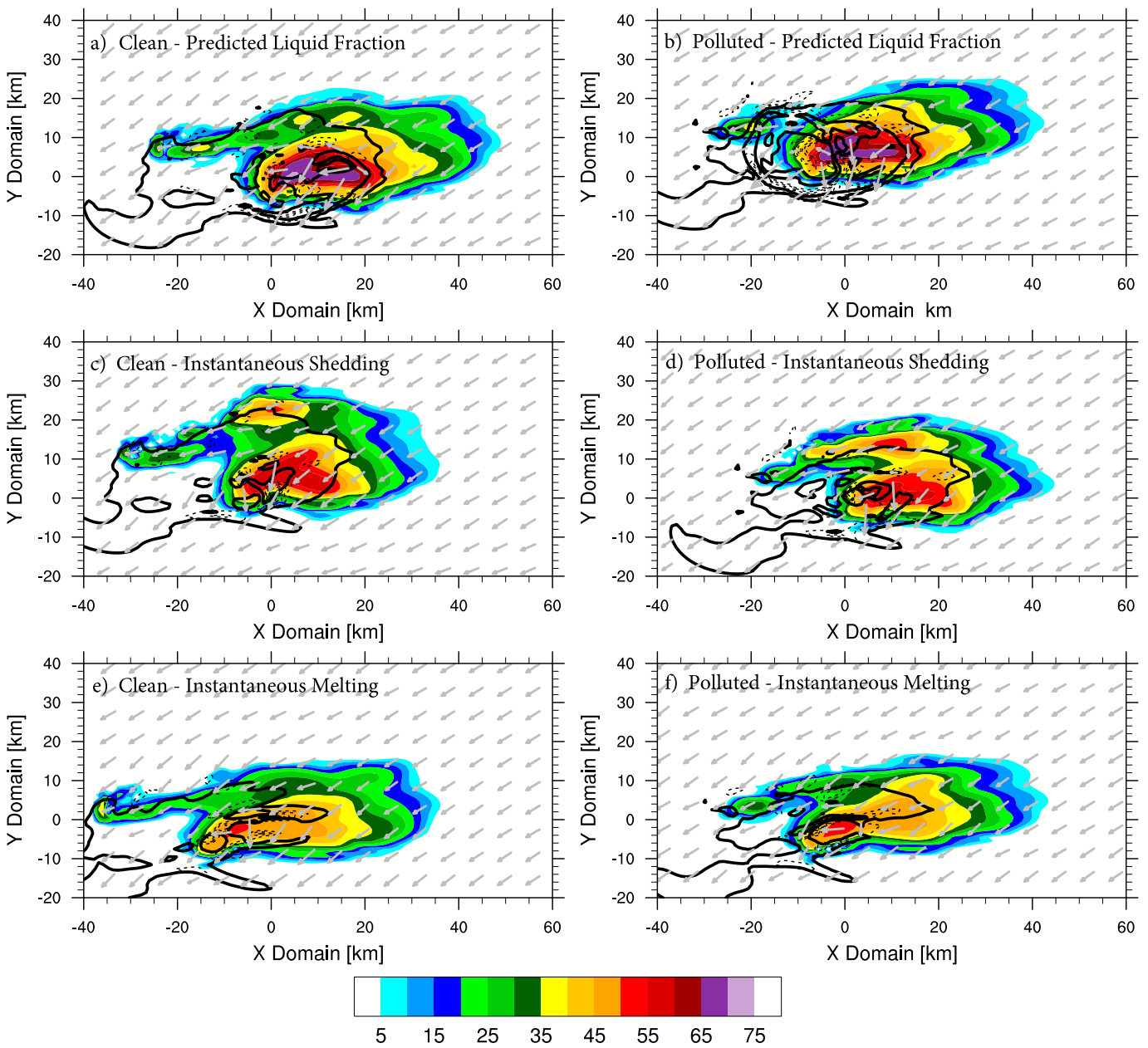

Simulated Radar Reflectivity [dBZ]

FIG. 6. Simulated radar reflectivity (shaded) at the lowest model level with surface wind vectors, surface convergence (black, dashed; interval of $0.002 \mathrm{~s}^{-1}$ ), and surface potential temperature perturbations (black, solid; -0.1 and $-1 \mathrm{~K}$ ) overlayed for the (a) predicted liquid fraction with $N_{a}=100 \mathrm{~cm}^{-3}$, (b) predicted liquid fraction with $N_{a}=500 \mathrm{~cm}^{-3}$, (c) instantaneous shedding with $N_{a}=100 \mathrm{~cm}^{-3}$, (d) instantaneous shedding with $N_{a}=500 \mathrm{~cm}^{-3}$, (e) instantaneous melting with $N_{a}=100 \mathrm{~cm}^{-3}$, and (f) instantaneous melting with $N_{a}=500 \mathrm{~cm}^{-3}$ at $1 \mathrm{~h}$. The domains are adjusted such that the origin in each panel is aligned with the location of the largest surface convergence.

nonexistent (instantaneous melting and predicted liquid fraction) or is present but weaker than the right-mover (instantaneous shedding).

The reflectivity field exhibits considerable differences between the simulations with different melting parameterizations and is less sensitive to the aerosol loading. As noted above, the predicted liquid fraction parameterization preserves graupel/hail below the melting level with a liquid coating, whereas the instantaneous shedding case can preserve large ice that is not coated with liquid and the instantaneous melting case preserves no ice; these differences are reflected in the reflectivity fields in Fig. 6. Specifically, the highest reflectivities are found in the predicted liquid fraction simulations, as indicated by the large swath of reflectivities exceeding 60 and even $65 \mathrm{dBZ}$ in Figs. 6a,b; we attribute this finding to the larger amount of graupel/hail coated in liquid as well as the presence of larger drops (3-4 mm in diameter) in these simulations, as shown in Figs. $2 \mathrm{e}, \mathrm{f}$, and 3 . The instantaneous shedding case results in slightly lower reflectivities (no region with reflectivities exceeding $60 \mathrm{~dB} Z$ due to the lack of liquid-coated hail) (Figs. 6c,d). The largest decrease in reflectivity is found for instantaneous melting, which is because no large frozen or partially melted hydrometeors are present below the melting level due to the instant 

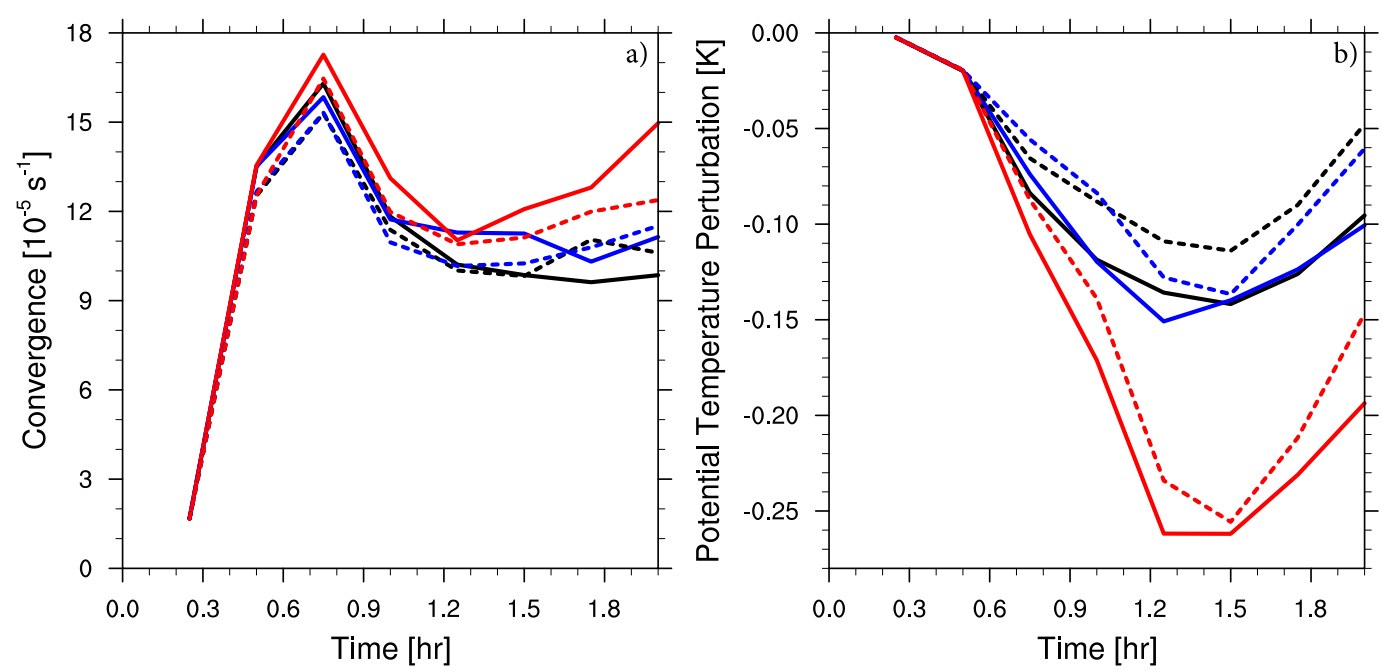

FIG. 7. (a) Mean convergence in the lowest model level and (b) mean negative potential temperature perturbation at the lowest model level for the predicted liquid fraction (black), instantaneous melting (blue), and instantaneous shedding (red) supercell simulations; clean (solid) and polluted (dashed) conditions are presented.

formation of large rain drops, some of which undergo spontaneous breakup, resulting in only a very small area of reflectivities exceeding $50 \mathrm{dBZ}$ (Figs. 6e,f).

There are also substantial structural differences between the simulations performed with different melting schemes. For the predicted liquid fraction and instantaneous shedding simulations, we find well-defined "hooks" in the reflectivity field, which coincide with a region of high convergence that forms the base of the updraft and an extended region (5-10 km in length) of convergence to the south and west that is representative of the rear flank downdraft (RFD). In the instantaneous melting simulations, the hook in the reflectivity field is less defined or essentially absent, and the areas of convergence are not aligned with the location of the mesocyclone.

Another important structural difference between the simulations is the presence of a left mover in the instantaneous shedding simulations, and thus a larger areal coverage of precipitation. This structural difference is critical in at least partially explaining the differences in the microphysical characteristics and precipitation discussed in sections $3 \mathrm{a}$ and $3 \mathrm{c}$. The only viable explanation for the formation and persistence of the left mover is the stronger cooling due to melting and evaporation at low levels (Figs. 4a,b), which permits sufficient convergence to enable the updraft to persist. This increase in low-level convergence (from a domainwide perspective) in the instantaneous shedding simulations is demonstrated in Fig. $7 \mathrm{a}$, and the mean negative potential temperature perturbation is shown in Fig. 7b. An additional important result here is that although instantaneous melting results in enhanced cooling rates near the melting level, this cool air has little to no impact on the potential temperature perturbations as well as convergence at the lowest model level. These results highlight the important sensitivity of supercellular convection (thermodynamics and dynamics) to seemingly small changes in the representation of microphysical processes.

Looking further at the thermodynamics at low levels, we find considerable differences in the cold pool structure between the simulations. Specifically, the cold pool is substantially smaller and disorganized in the instantaneous melting case, which is attributed to cooling via melting and subsequent evaporation occurring at higher levels, as shown in Figs. 4a,b, and 6. Although the instantaneous melting imparts a thermodynamic impulse just below the melting level, the associated cooling is not translated to the surface (see also Fig. 7b). This suppression in the cold pool under instantaneous melting coincides with the reduced convergence discussed above (Fig. 7a). As indicated above in the context of the reflectivity field, the impact of changes in aerosol loading on both the surface thermodynamics and convergence are largely outweighed by changes in the melting parameterization, although this should be expected given the small differences in the cooling rates between the simulations with different aerosols compared to different melting representations shown in Figs. 4a,b.

The impacts of the different melting schemes on the dynamics of the simulated supercell storm extend beyond just the surface. To illustrate the more indirect impacts on the storm dynamics, PDFs of updraft and downdraft mass fluxes are presented in Fig. 8. The enhanced cooling from instantly melted falling ice and subsequent evaporative 


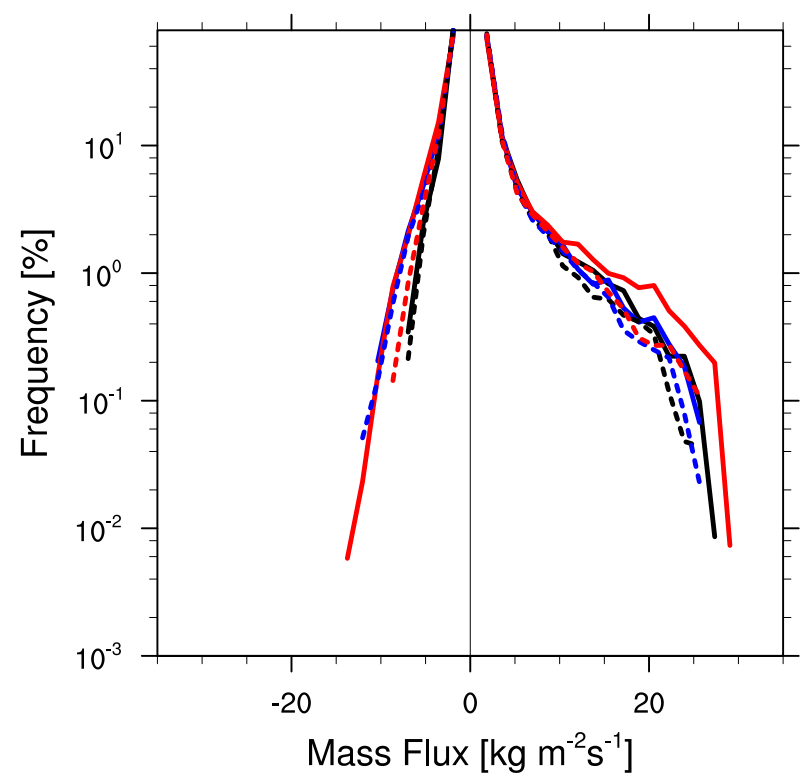

FIG. 8. PDF of updraft and downdraft mass fluxes (product of vertical velocity and air density; $1-2 \mathrm{~h}$ ) for the predicted liquid fraction (black), instantaneous melting (blue), and instantaneous shedding (red) supercell simulations with initial aerosol concentrations of $100 \mathrm{~cm}^{-3}$ (solid) and $500 \mathrm{~cm}^{-3}$ (dashed). The PDFs are computed separately for positive and negative velocities.

cooling shown in Fig. 4 is indicative of stronger downdrafts. However, these stronger downdrafts are not conducive to stronger updrafts, which is also illustrated in Fig. 8 for the case of instantaneous melting, suggesting a disconnect between the location of low-level convergence and the mesocyclone.
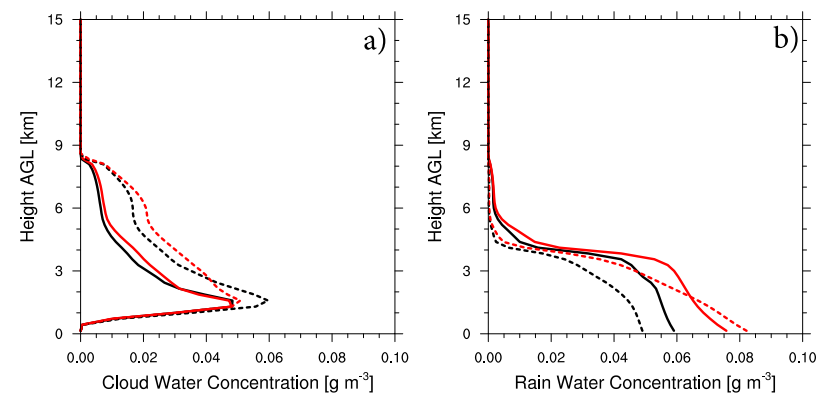

Especially in the clean instantaneous shedding case, there is evidence of stronger downdrafts and updrafts. The latter of which is conducive to higher condensate loading and precipitation, as demonstrated above in Figs. $2 \mathrm{~g}$ and 5 and Table 2 . These stronger updrafts are also conducive to the formation of larger hail, thus resulting in a larger fraction of precipitation reaching the surface as ice (Table 2). Again, these results highlight the important role of the representation of melting and shedding on the evolution and structure of supercellular convection, extending beyond just direct impacts on the low-level thermodynamics.

\section{Squall line \\ a. Microphysical characteristics}

Analogous to the supercell results described in section 3, the bulk microphysical properties of the simulated squall lines also exhibit large sensitivity to the choice of melting scheme, and, for certain species, the ambient aerosol loading as well, as portrayed in Fig. 9. The differences induced by changing the melting parameterization are quite similar between the two systems. For example, we again find little sensitivity in the cloud water concentration (Fig. 9a) except for an increase above approximately $1.5 \mathrm{~km}$ for increased aerosol loading. However, this should be expected owing to the suppression of warm rain processes under the presence of more aerosol particles. This is further confirmed by the decrease in rainwater content with increased aerosol loading, as in the supercell case.
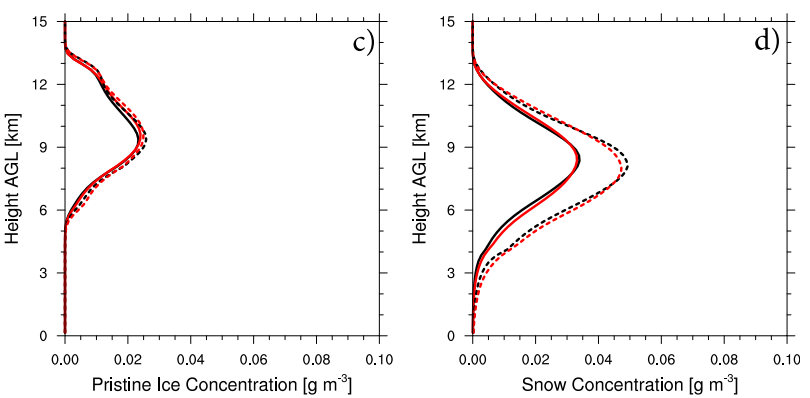
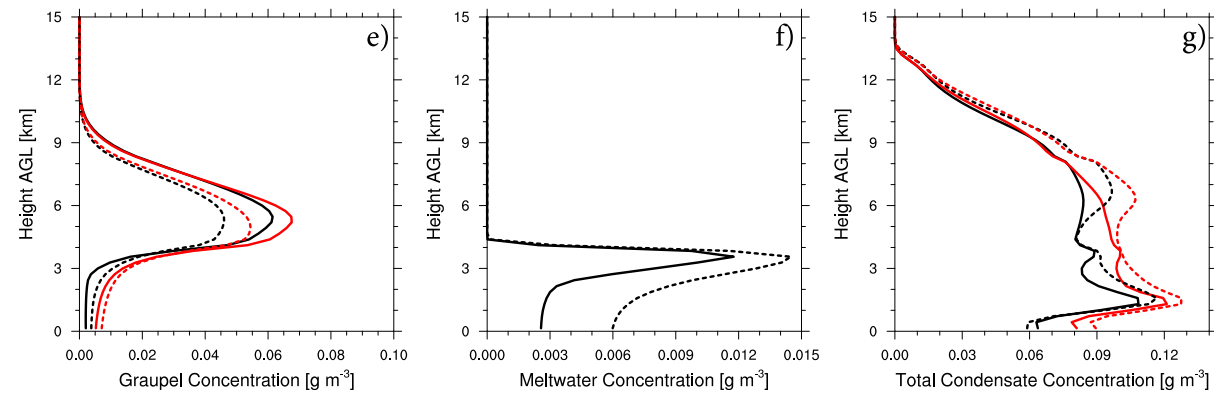

FIG. 9. As in Fig. 2, but for the squall-line simulation and temporally averaged over $2-4 \mathrm{~h}$. 
Furthermore, a key difference in the profiles of the rainwater content below the melting level between the squall-line and supercell cases is that there appears to be less sensitivity to the melting parameterization for the squall-line case and more sensitivity to the aerosol loading; this difference is related to structural differences between squall lines and supercells, whereby the former promotes the formation of large amounts of less dense ice (i.e., snow and pristine ice), which are prevalent in the trailing stratiform region (TSR) of the system. Thus, the mechanism by which large amounts of rain are formed differs between these systems, and this is reflected in the rain concentration profiles. Again, the monotonic increase in rainwater moving toward the surface is due to the continuous production of rainwater below the melting level in both the predicted liquid fraction and instantaneous shedding simulations as well as mass convergence owing to the reduction in drop sizes due to evaporation as particles descend toward the ground.

Regarding the frozen hydrometeors, we see a general increase in snow mass aloft with increased aerosol loading, with much less sensitivity to aerosol loading and melting parameterization in the pristine ice concentration profiles (Figs. 9c,d). The additional snow with increased aerosol loading occurs at the expense of graupel/hail aloft (Figs. 9d,e). The combined results of Figs. 9c-e indicate that the simulations with increased aerosol loading preferentially partition freezing liquid hydrometeors into the pristine ice category owing to their smaller size, but these frozen droplets are quickly converted to the snow category due to aggregation and the riming of small supercooled droplets. The reason that this change in partitioning of frozen hydrometeors was not evident in the supercell simulations is that the very strong updrafts support the formation of large drops that freeze into the graupel/hail category in the model, essentially regardless of the aerosol loading. In the squall-line case, the weaker updrafts of the system combined with increased aerosol loading leading to smaller drops results in preferential partitioning to the pristine ice (and then snow) category.

Furthermore, we find evidence of partially melted snow below the melting level in the predicted liquid fraction simulations, which was not seen in the supercell simulations, although this should be expected given the extent of stratiform precipitation formed in the trailing stratiform region of typical squall lines (which is discussed in more detail in the following subsections); the precipitation in this region of a typical squall line is largely formed from the melting of less dense ice (i.e., snow).

Regarding the graupel/hail concentrations, rather larger differences are also evident between the simulations with different melting parameterizations as well as aerosol loadings (Fig. 9e). Unlike the supercell case in which the graupel/hail decreased quite gradually moving toward the surface (Fig. 2e), we find a rapid decrease in graupel/hail just below the melting level that levels off quite quickly in the squall-line case. This difference can be attributed to the production of generally smaller graupel/hail due to the weaker updrafts in the simulated squall line as well as the higher relative humidities below the melting level (Fig. 1).

Figure 9f shows the meltwater concentration for the predicted liquid fraction simulations. From a domainwide perspective, the mass concentration of meltwater retained on melting graupel/hail ${ }^{5}$ is more than the graupel/hail mass concentration itself near the surface (i.e., the hydrometeors are essentially large raindrops with small residual ice cores); in fact, at the surface, the mass concentration of meltwater represents up to $50 \%$ of the total hydrometeor mass (with even higher fractions of meltwater between 1 and $3 \mathrm{~km}$ above the surface); this is no surprise given the high relative humidities near the surface and extended upward to nearly $700 \mathrm{mb}$; this region of high humidity is rather limited in the supercell case, thus limiting the potential for melting in the supercell case (Fig. 1).

The total condensed concentration profiles are shown in Fig. 9g, which reflect a combination of the individual changes discussed above for each species. In general, even with the large differences between the simulations with different aerosol loadings and different melting parameterizations, the predicted liquid fraction and instantaneous shedding simulations produce fairly similar total condensate concentration profiles, although the latter generally has more condensate throughout the column, as was the situation in the supercell case.

\section{b. Thermodynamic response}

Cold pool characteristics are strongly tied to the size, speed, tilt, and updraft strength of squall lines (e.g., Rotunno et al. 1988; Parker 2010; Lebo 2018). Figure 10a shows the evaporative cooling rate near and below the melting level. The predicted liquid fraction and instantaneous shedding simulations produce very similar evaporative cooling profiles, with increased aerosol loading resulting in larger evaporative cooling rates (Fig. 10a). Owing to the nearly identical amount of total condensate aloft (Fig. 9g), the increase in evaporative cooling at low levels results in reduced rainwater in the simulations with higher aerosol loading (Figs. 9b and 10c). This sensitivity to aerosol is larger in the predicted

\footnotetext{
${ }^{5} \mathrm{We}$ restrict this analysis to graupel/hail because the liquid from partially melted snow, although present below the melting level, is quickly lost.
} 

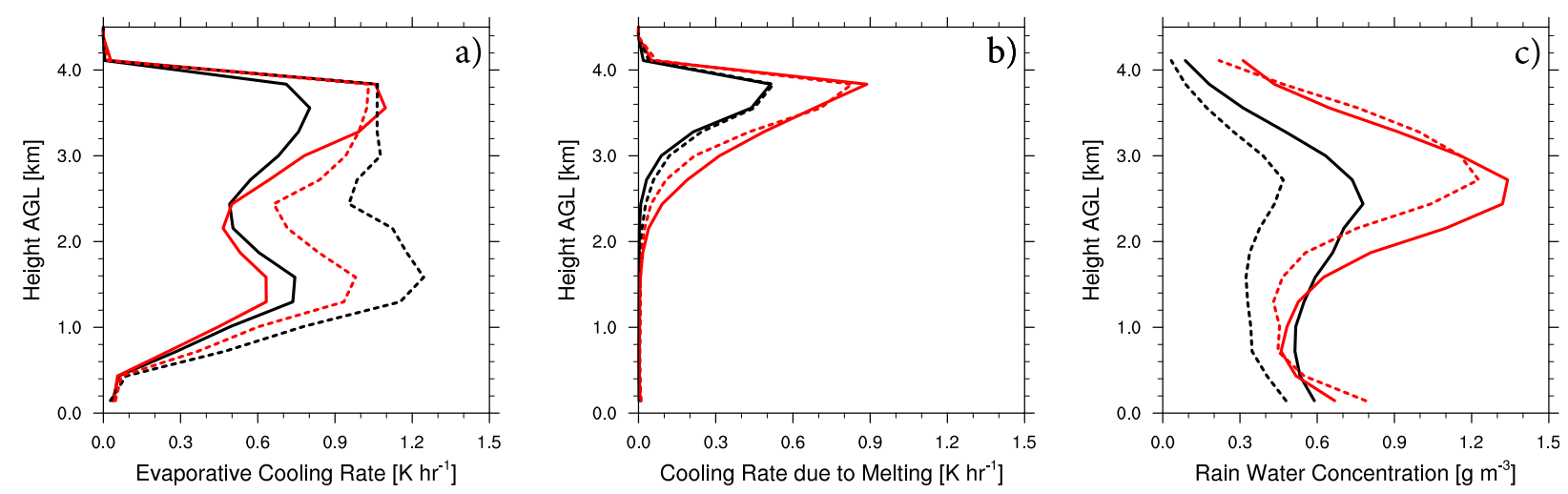

FIG. 10. As in Fig. 4, but for the squall-line simulations.

liquid fraction simulations, resulting in a more pronounced decrease in rainwater with increased aerosol loading. We attribute this difference to the propensity for more snow to be formed in the squall line with increased aerosol loading, which does not result in hydrometeors of the same size as those in the graupel/hail category, thus melting into smaller drops and a subsequently higher evaporation rates.

With regard to melting, the associated cooling rate is substantially higher in the instantaneous shedding case, with the aerosol difference playing a very minor role (Fig. 10b). The larger melting rate in the instantaneous shedding simulations, regardless of the aerosol loading, is in line with the rapid reduction in the graupel/hail concentrations just below the melting level (Fig. 9e), whereby the instantaneous shedding simulations have more graupel/hail above the freezing level, and the difference is quickly reduced to nearly zero at a height of $3.5 \mathrm{~km}$. Moreover, this increase in melting in the instantaneous shedding case results in the increase in rainwater shown in Fig. 10c. Furthermore, as also shown in the supercell results, the cooling due to melting is of similar magnitude, especially near the melting level; this finding again highlights the important of melting in deep convective clouds.

Because of the tight coupling between cold pool characteristics and squall-line structure (e.g., Rotunno et al. 1988), particularly the vertical structure of the cold pool and not just the surface characteristics, the lowlevel thermodynamic environment is examined in the squall-line cases by computing the cold pool intensity (c), which is formulated as follows (e.g., Rotunno et al. 1988; Markowski and Richardson 2010):

$$
c=\sqrt{-2 \int_{0}^{H} B_{L} d z},
$$

where the buoyancy $\left(B_{L}\right)$ is computed from the surface to the top of the cold pool $(H)$ at some point behind the leading edge of the cold pool $(L)$. Here, the cold pool boundaries are defined based on neutral buoyancy. $B_{L}$ includes the effects of temperature perturbations, humidity, and hydrometeor loading. Due to the spatial variability of the low-level thermodynamic environment and microphysical properties, $c$ exhibits large spatial variability. Thus, $c$ is computed by taking the horizontal average over the $y$ direction and a swath in the $x$ direction that is $30 \mathrm{~km}$ wide and trails the edge of the cold pool (e.g., Lebo 2014; Xue et al. 2017); the results are found to be qualitatively insensitive to small changes in the width and location of the averaging region.

Although the differences in the cold pool strength presented in Fig. 11 (represented as $c$ relative to the vertical change in the zonal wind over $4 \mathrm{~km}, \Delta u$, which is the depth of the shear layer) are generally quite small between the simulations, there is a tendency for $c / \Delta u$ to be slightly higher in the simulations with instantaneous shedding. The main reasons for this increase are increased hydrometeor loading, specifically graupel/hail and rain near the surface (Figs. 9b,e), and increased cooling due to melting (Fig. 4c).

We also find a tendency, especially for the first half of the simulations, for the cold pool strength to be weaker under higher aerosol loadings, which has been shown in prior studies (e.g., Lebo and Morrison 2014; Lebo 2014); the period of which the cold pool strength is weaker is longer for the instantaneous shedding simulation with high aerosol loading than that of the counterpart predicted liquid fraction simulation. This indicates perhaps a slow spinup of the squall line and could result in different propagation characteristics owing to the relation between $c$ and cold pool propagation speed.

\section{c. Precipitation response}

Although the predicted liquid fraction and instantaneous shedding simulations result in somewhat similar total condensate profiles, the resultant precipitation amounts differ 


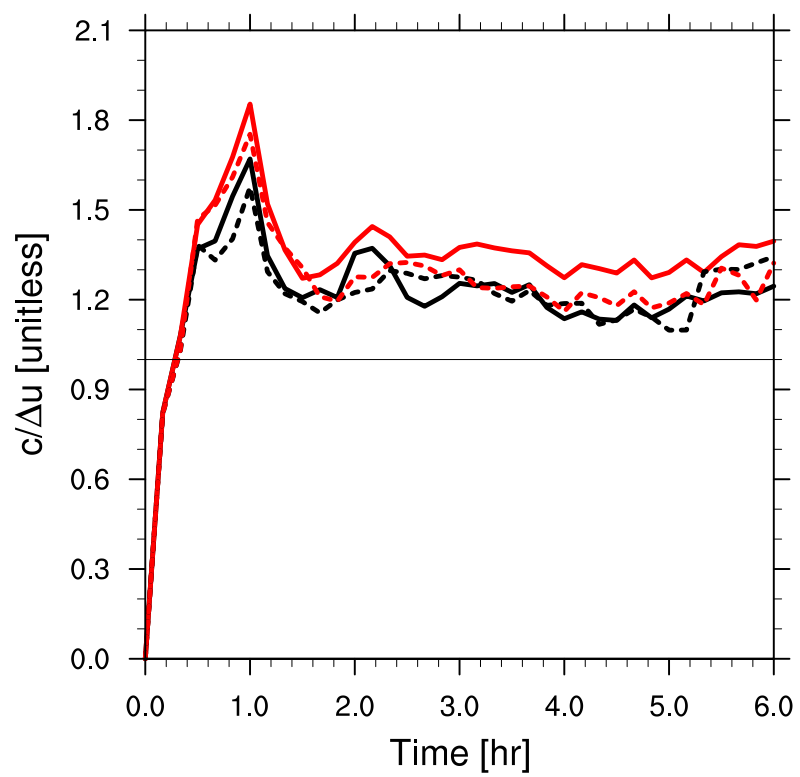

FIG. 11. Time series of $c$ relative to $\Delta u$; a value of 1 indicates a relatively upright convective line according to Rotunno et al. (1988). The curves represent the predicted liquid fraction (black) and instantaneous shedding (red) squall-line simulations with initial aerosol concentrations of $100 \mathrm{~cm}^{-3}$ (solid) and $500 \mathrm{~cm}^{-3}$ (dashed).

between the simulations, as shown in Fig. 12 and Table 3. The results for the squall line differ from those of the supercell owing to the strong relation between cold pool strength and propagation speed of the former. Because we are concerned with cumulative precipitation in Fig. 12, propagation speed can impact accumulation amounts. For example, a faster-moving squall line, even with the same precipitation rate, will disperse the precipitation over a larger area with smaller total amounts at any given location, and vice versa. Obviously, if the precipitation rate, which is related to the production of rainwater, is different, the influence of propagation speed on cumulative precipitation becomes confounded with other factors. This is precisely what the simulations suggest. Figure 12 and Table 3 indicate higher precipitation amounts both in terms of a longer tail of the cumulative precipitation PDF as well as a higher mean, respectively. This contradicts the notion that the squall line should propagate faster owing to the stronger cold pool. However, as shown in Fig. 2g, the total condensate is higher in the instantaneous shedding simulations, which is largely a result of more graupel/hail and more rain. This increase in condensate is related to dynamical effects of the different melting parameterizations, which is discussed in the following subsection.

\section{d. Storm structure and simulated radar reflectivity}

The TSR of squall lines is often misrepresented in simulations, which is largely related to a model's

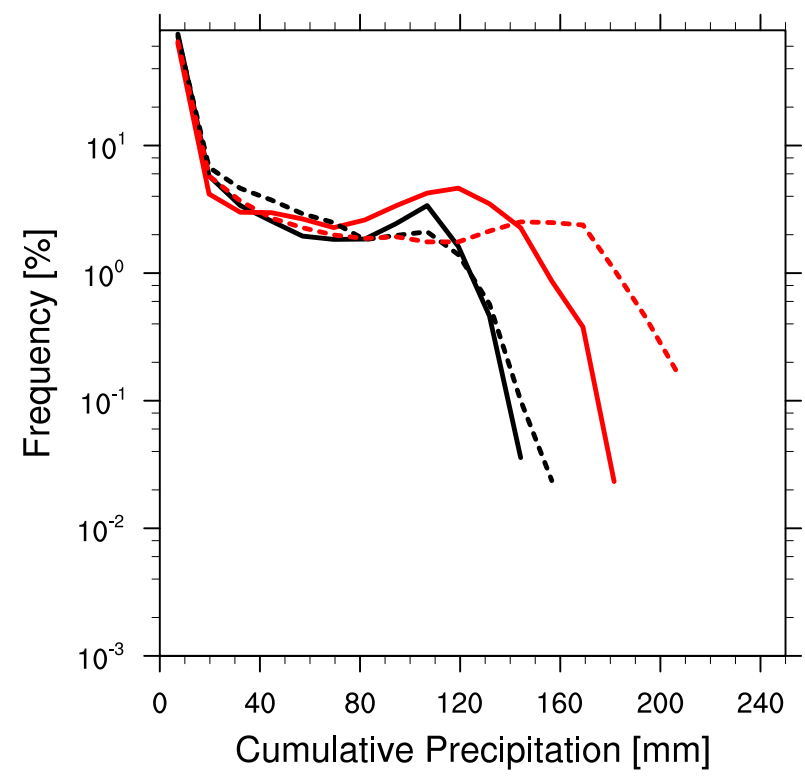

FIG. 12. As in Fig. 5, but for the squall-line simulations.

representation of ice (e.g., Fovell and Ogura 1988). Recent advancements in microphysics parameterizations have resulted in better representations of the TSR (e.g., Morrison et al. 2009; Jensen et al. 2018), although an explicit representation of retained meltwater and shedding that is not constrained by predefined size distribution functions is often excluding in such models. Given the aforementioned differences in the frozen hydrometeor species (Figs. 9c-e), the production of rain below the melting level (Fig. 9b), and the large meltwater component on falling graupel/hail in the predicted liquid fraction simulations (Fig. 9f), it is expected that differences in the trailing stratiform and convective core regions of the simulated squall line should be evident.

Transects (averaged along the $y$ axis) of vertical velocity and equivalent potential temperature at $2.5 \mathrm{~h}$ into the simulations are shown in Fig. $13 .{ }^{6}$ Here, we see evidence of the different propagation speeds that were indicated by the thermodynamic analysis of the cold pool strength in the prior subsection. The higher $c / \Delta u$ values for the instantaneous shedding are represented in the transect as a shift to the right (i.e., indicative of a faster propagation speed) by approximately $5 \mathrm{~km}$ after $2.5 \mathrm{~h}$ (i.e., a difference in the mean propagation speed of approximately $2 \mathrm{~m} \mathrm{~s}^{-1}$ ).

\footnotetext{
${ }^{6}$ Owing to the differing evolution of the simulated squall lines with different aerosol loadings or melting parameterizations, temporal compositing of the simulated fields results in smoothed fields that are not representative of the mature system.
} 
TABLE 3. As in Table 2, but for the squall-line simulations.

\begin{tabular}{lll}
\hline \hline & $\begin{array}{c}\text { Predicted liquid } \\
\text { fraction }\end{array}$ & $\begin{array}{c}\text { Instantaneous } \\
\text { shedding }\end{array}$ \\
\hline$N_{a}=100 \mathrm{~cm}^{-3}$ & $5.81 \mathrm{~mm}(3.8 \%)$ & $8.71 \mathrm{~mm}(9.3 \%)$ \\
$N_{a}=500 \mathrm{~cm}^{-3}$ & $4.75 \mathrm{~mm}(11.5 \%)$ & $7.59 \mathrm{~mm}(14.3 \%)$ \\
\hline
\end{tabular}

There are also differences in the convective core region between the simulations, with the largest differences being found between the simulations run with different representations of melting. The convective core region is generally represented by broader updrafts in the instantaneous shedding simulations (and an increase in the total updraft mass flux of approximately $10 \%$; not shown), which is again in line with the aforementioned analysis of the cold pool characteristics and prior results (e.g., Lebo and Morrison 2014). This increase in the updraft mass flux is also important for explaining the aforementioned increase in condensate and precipitation (Fig. 9g and Table 3).

Figure 13 also provides evidence of changes in the rearinflow jet (RIJ). Comparing the results for the simulations with predicted liquid fraction and instantaneous shedding, we find lower $-\theta_{e}$ air reaching lower levels in the case of the latter. In fact, the $328-\mathrm{K}$ isentrope nearly reaches the surface in the clean instantaneous shedding simulation, whereas it only descends to a height of approximately $1 \mathrm{~km}$ in the simulation with predicted liquid fraction. Granted, the downdraft velocities appear to be similar between these two simulations performed with different melting parameterizations. However, owing to the higher condensate loading, primarily in the form of rainwater (Fig. 9b), and increased cooling rates due to evaporation (mostly near the melting level) and melting (Figs. 10a,b) in the instantaneous shedding simulation, the downward mass flux of the RIJ is larger and is exhibited by increased negative buoyancy. This results in larger horizontal wind velocities near the surface (not shown) and is in line with the higher propagation speed in the instantaneous shedding simulations.

The aforementioned changes in updraft and cold pool structure due to melting and changes in aerosol loading are expected to impact the radar reflectivity field of the idealized squall line. Figure 14 shows the simulated reflectivity averaged along the $y$ axis of the domain. As expected, the predicted liquid fraction simulations generally have higher reflectivity signatures than the instantaneous shedding simulations below the melting level, which is similar to the results presented earlier for the supercell case (see Fig. 6). This is largely related to the presence of liquid-coated graupel/hail hydrometeors that are absent in the instantaneous shedding simulations, a) Clean - Predicted Liquid Fraction
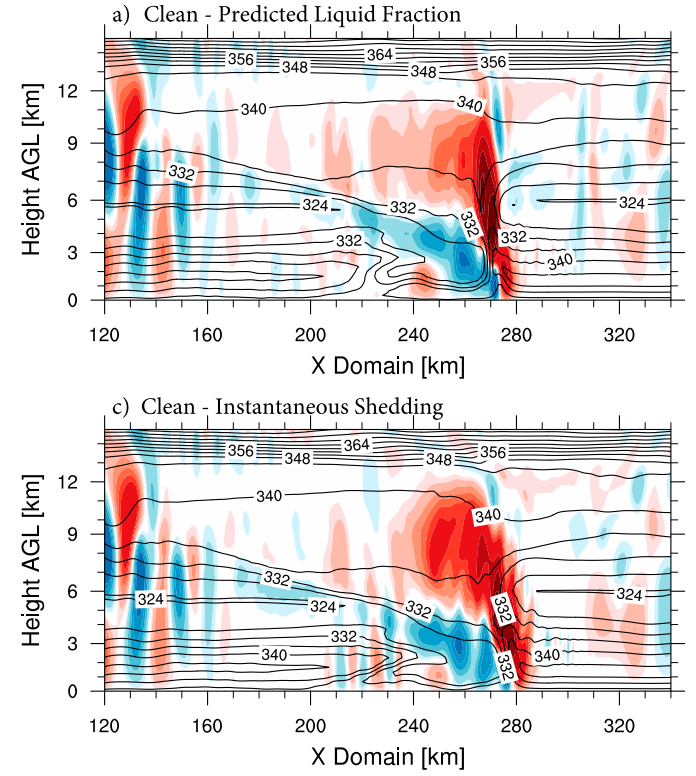

b) Polluted - Predicted Liquid Fraction

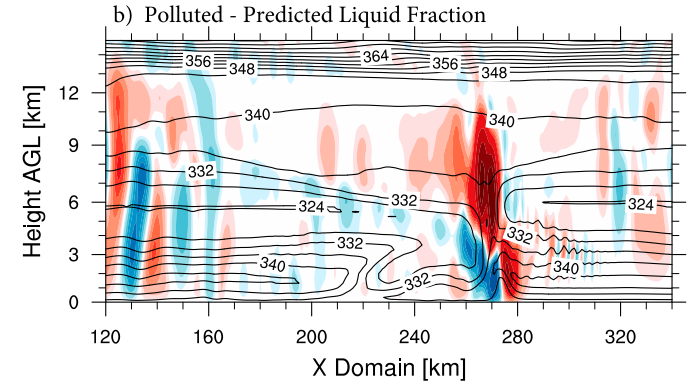

d) Polluted - Instantaneous Shedding

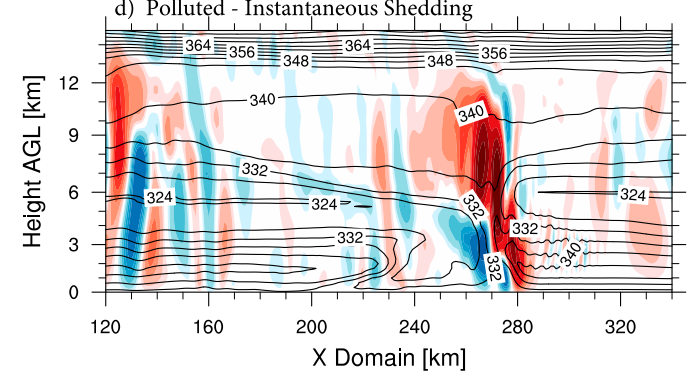

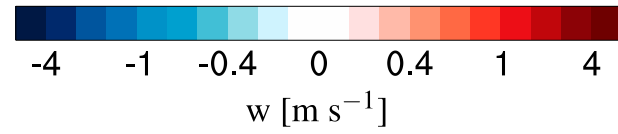

FIG. 13. Cross sections of $\theta_{e}$ (contoured) and $w$ (shaded) averaged in the $y$ direction at $2.5 \mathrm{~h}$ for (a) predicted liquid fraction with $N_{a}=100 \mathrm{~cm}^{-3}$, (b) predicted liquid fraction with $N_{a}=500 \mathrm{~cm}^{-3}$, (c) instantaneous shedding with $N_{a}=100 \mathrm{~cm}^{-3}$, and (d) instantaneous shedding with $N_{a}=500 \mathrm{~cm}^{-3}$. 

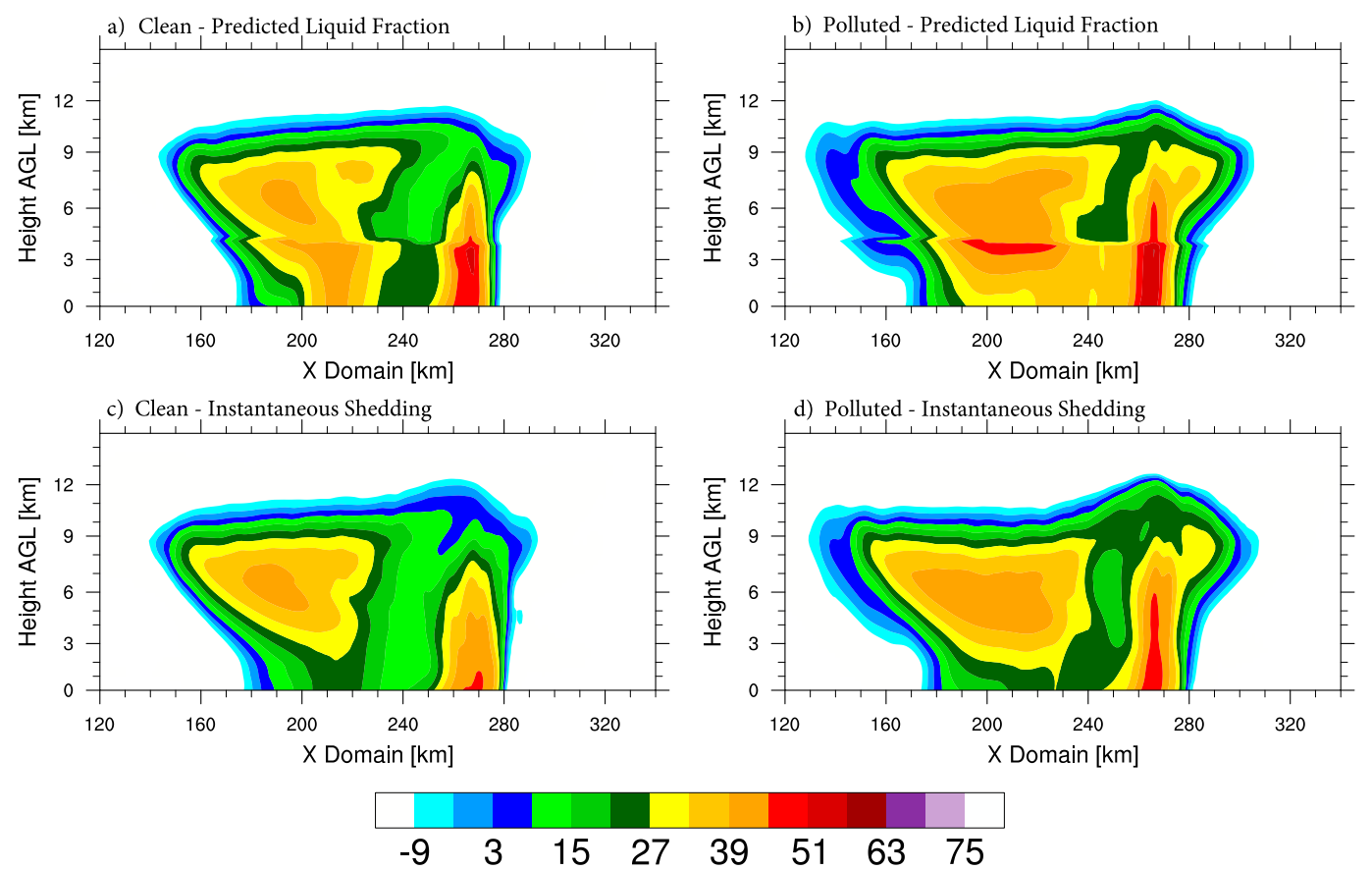

Simulated Radar Reflectivity [dBZ]

FIG. 14. As in Fig. 13, but for the simulated reflectivity; note the difference in color bars with Fig. 6, which is intended to better portray the extent of the simulated squall line.

which results in the commonly observed "bright band". Above the melting level, the reflectivities are slightly higher in the instantaneous shedding simulations (as indicated by the broader region of reflectivities exceeding $39 \mathrm{dBZ}$ ); the reflectivities are also higher in the simulations with increased aerosol loading, especially in the trailing stratiform region where there is more snow (Fig. 9d).

Interestingly, regardless of the melting parameterization or aerosol loading, all simulations produce a horizontal radar reflectivity field characterized by high values within the leading edge and convective cores, a lull following the convective region, and enhanced reflectivities again in the TSR for a sustained amount of time, which is commonly observed in real squall lines (e.g., Braun and Houze 1994). The reflectivities at the leading edge of the simulated squall lines are generally higher in the predicted liquid fraction results, which is related to the presence of large ice (graupel/hail), which has a substantially higher fall speed than other hydrometeors and thus falls out shortly behind the updraft cores. This shift in the location of the updraft cores relative to the falling large, dense is evident by comparing the location of the low-level updrafts in Fig. 13 and the peak reflectivities in Fig. 14, where the latter trails the former by approximately $10-20 \mathrm{~km}$.

To take a closer look at this low-level reflectivity structure, a plan view of the reflectivity field at a height of $3.5 \mathrm{~km}$ and at $2.5 \mathrm{~h}$ into the simulations is shown in Fig. 15 .
Note that some differences are evident between the mean reflectivity cross sections shown in Fig. 14 and the plan view in Fig. 15, owing to the effects of averaging in space. At $2.5 \mathrm{~h}$, the structure of high reflectivities in the convective core region, a lull, and then enhanced reflectivities again in the TSR is evident in all simulations, albeit to varying degrees. This transition region is generally more pronounced in the case of predicted liquid fraction.

Figure 15 also indicates the presence of the well-known bright band in the predicted liquid fraction simulations extending throughout the entire TSR, as expected. The TSR is evident in the simulations performed with instantaneous shedding, albeit the reflectivities are much lower than expected in the presence of melting hydrometeors. A similar decrease in reflectivities moving from the predicted liquid fraction simulations to instantaneous shedding is also found in the vicinity of the convective cores owing to the presence of large, dense ice falling and becoming partially melted.

We further explore the impacts of the representation of melting on the evolution of the simulated squall line by examining cross sections of the reflectivity at $1.5 \mathrm{~h}$ later in time (i.e., $4 \mathrm{~h}$ ), which is shown in Fig. 16. Regardless of the melting parameterization or aerosol loading, we see evidence of broadening of the trailing stratiform region compared with the prior time (Fig. 14), which is related to a portion of the rear inflow turning 

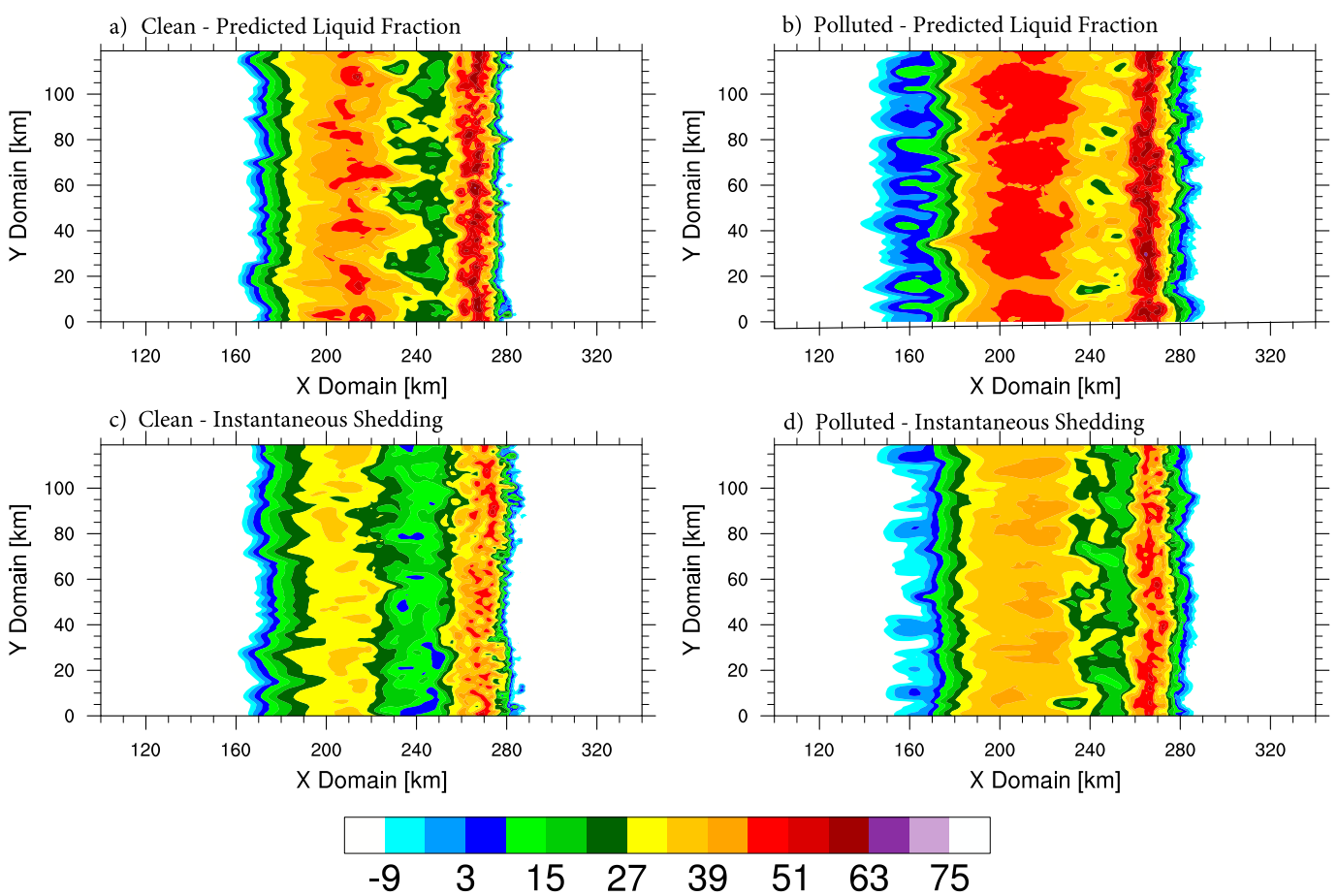

Simulated Radar Reflectivity [dBZ]

FIG. 15. Plan view of the simulated reflectivity field at a height of $3.5 \mathrm{~km}$ and at $2.5 \mathrm{~h}$ (corresponding to the same time shown in Figs. 13 and 14) for (a) predicted liquid fraction with $N_{a}=100 \mathrm{~cm}^{-3}$, (b) predicted liquid fraction with $N_{a}=500 \mathrm{~cm}^{-3}$, (c) instantaneous shedding with $N_{a}=100 \mathrm{~cm}^{-3}$, and (d) instantaneous shedding with $N_{a}=500 \mathrm{~cm}^{-3}$.

westward (left) upon reaching the surface. There is still evidence of a transition region between the TSR and convective core region at this time, albeit it is less pronounced in the simulations with increased aerosol loading. This result highlights the important role of the partitioning of ice species in the ability of numerical models to represent such commonly observed features. Moreover, we see evidence of convection dissipating by $4 \mathrm{~h}$ in the instantaneous shedding simulations, especially in the case of low aerosol loading. This is evidenced by the decrease in reflectivities in the core region and increase in the trailing stratiform region at low levels, which indicates a lack of upper-level mesoscale ascent supporting larger hydrometeor growth in the case of instantaneous shedding.

The combination of the results presented in Figs. 14, 15, and 16 in addition to Fig. 12 confirm that the use of a predicted liquid fraction parameterization is critical for simulating cumulative precipitation as well as squall-line structure and evolution.

\section{Conclusions}

\section{a. Summary}

The primary goal of this study is to use a bin microphysics model, containing a thorough and physically based representation of melting, to examine the dynamic and thermodynamic impacts of different melting representations on idealized supercell and squall-line cases in a 3D dynamical model. Melting is considered to result in the retention of meltwater until certain criteria are met (physically based), instantaneous shedding (analogous to the prior case except that meltwater is instantly shed as rain drops assuming the mean ice size remains constant, as is done in nearly all bulk microphysics schemes), or completely instantaneous. Impacts due to aerosol loading adjustments are also considered by simulating a clean environment $\left(100 \mathrm{~cm}^{-3}\right)$ and a more polluted environment $\left(500 \mathrm{~cm}^{-3}\right)$ because of the expected impact on ice formation and partitioning aloft.

Most microphysics models treat the melting of pristine ice instantaneously, and they also do not account for liquid retention and shedding for melting snow and graupel/hail hydrometeors, which was hypothesized to resulted in increased evaporation and subsequent melting rates. Instead, they typically use an analytic solution integrated over the ice size distribution based on balancing the heat budget, and the newly formed meltwater is transferred to rain immediately in the case of many bulk microphysics schemes, not allowing for the retention of meltwater on the surface of melting ice. 

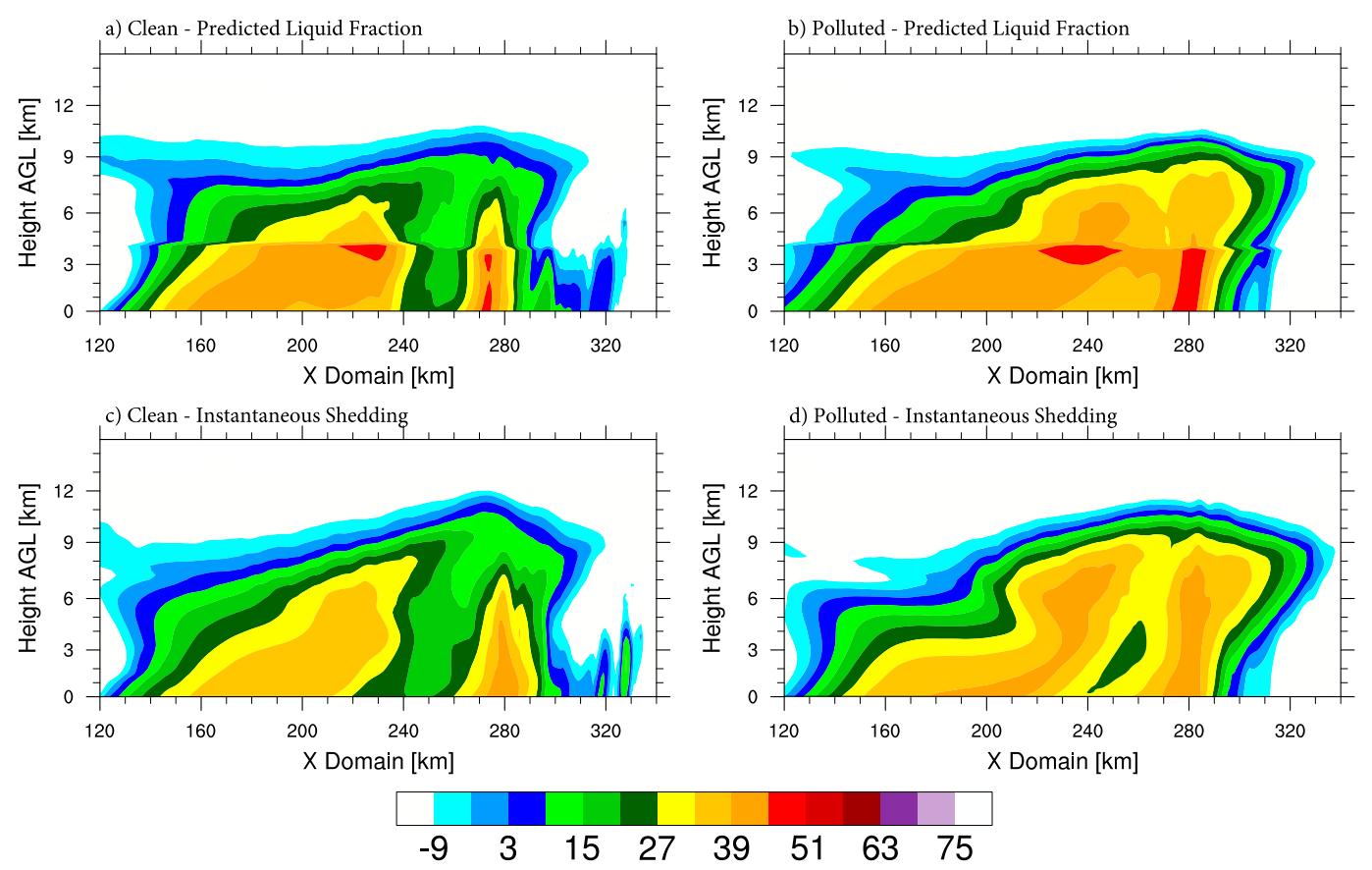

Simulated Radar Reflectivity [dBZ]

FIG. 16. As in Fig. 14, but at $4 \mathrm{~h}$.

Similarly, liquid water accreted on melting ice is commonly assumed to be shed instantly.

For the different melting assumptions used in this study, compared with the more realistic melting process (i.e., predicted liquid fraction), instantaneous melting leads to excessive melting and evaporation, ultimately impacting the overall mature storm structure. In the case of instantaneous shedding, the results are more similar to the predicted liquid fraction results, albeit with generally enhanced evaporation/melting and suppressed reflectivities owing to the lack of meltwater retention and the production of numerous shed drops (which are smaller than the larger ice that they are derived from).

More specific conclusions are as follows:

- For most aspects of the simulated supercell storm and squall line (e.g., precipitation, condensate loading, storm structure and evolution), changing the melting parameterization has a larger impact on the results than changing the aerosol concentration by a factor of 5 .

- Melting is nonnegligible in terms of the energy budget within these idealized convective simulations; under certain conditions, the cooling rate due to melting can exceed that of evaporation below the melting level.

- Supercell structure is found to depend on the assumed melting paradigm, with the predicted liquid fraction and instantaneous shedding simulations resulting in well-defined "hooks" in the reflectivity field, an elongated RFD, and a focused convergence zone near the base of the mesocylone; these features are suppressed or even absent in the simulations using instantaneous melting owing to the misrepresentation of the thermodynamics below the melting level.

- Meltwater retained on hydrometeors below the melting level can exceed the amount of ice at the core of these hydrometeors.

- Models using instantaneous shedding, as in most bulk schemes, may be artificially enhancing the propagation of squall lines via stronger cold pools and affecting the simulated storm evolution.

\section{b. Discussion}

The results presented in sections 3 and 4, although based on idealized simulations, shed some light on the role of melting in convective storms at scales ranging from the microscale to mesoscale. One of the key results is related to the different storm evolution for the three different melting parameterizations employed in this study, highlighting the importance of predicting the liquid fraction of melting hydrometeors and the retention of meltwater on the structural evolution of convective systems, at least based on the idealized simulations of a supercell and squall line.

A critical factor, however, is that the melting rate can be largely tied back to the ambient humidity below the 
melting level (e.g., Phillips et al. 2007), whereby moist environments exhibit more rapid melting than drier environments. The reason for this difference lies in the rate at which meltwater evaporates. In humid environments, the retained meltwater exhibits a smaller evaporation rate and is thus less efficient at cooling the graupel/hail hydrometeor, causing the hydrometeors to melt rapidly. On the contrary, in drier environments, the aforementioned evaporative cooling will initially allow the hailstones to penetrate closer to the surface, where the environmental temperatures are higher, and this may conceivably enhance the overall melting and counterbalance the evaporative cooling effect (as shown in Fig. 4b).

The results presented herein cannot be generalized to all MCSs; this would require far more case studies and detailed comparisons with observables, which goes beyond the scope of this work. Instead, the importance of melting and its precise representation in models is accentuated, especially with regard to near-real-time models like the High-Resolution Rapid Refresh (HRRR) model (Benjamin et al. 2016) for convective storm forecasting. Future studies giving special attention to the representation of melting in numerical models is warranted based on the findings of this study. Future model improvements should focus on the representation of melting, including the prediction of meltwater retention and shedding, especially as computing resources increase and more detailed physics can be included. Moreover, future efforts should aim to better understand other aspects of melting and shedding in the context of deep convective clouds (e.g., the role of the shed drop sizes as well as the importance of the amount of water retained on the surface of melting graupel/hail, which is likely affected by tumbling).

Acknowledgments. Partial support for this work was provided by Department of Energy grant DE-SC0016354 (ZJL) and the University of Wyoming (KGK and ZJL). We would also like to acknowledge high-performance computing support from Cheyenne (Computational and Information Systems Laboratory 2017) provided by NCAR's Computational and Information Systems Laboratory and sponsored by the National Science Foundation.

\section{REFERENCES}

Altaratz, O., I. Koren, L. Remer, and E. Hirsch, 2014: Review: Cloud invigoration by aerosols-Coupling between microphysics and dynamics. Atmos. Res., 140-141, 38-60, https:// doi.org/10.1016/j.atmosres.2014.01.009.

Benjamin, S. G., and Coauthors, 2016: A North American hourly assimilation and model forecast cycle: The Rapid Refresh. Mon. Wea. Rev., 144, 1669-1694, https://doi.org/10.1175/MWRD-15-0242.1.

Berg, W., T. L'Ecuyer, and S. van den Heever, 2008: Evidence for the impact of aerosols on the onset and microphysical properties of rainfall from a combination of satellite observations and cloudresolving model simulations. J. Geophys. Res., 113, D14S23, https://doi.org/10.1029/2007JD009649.

Bigg, E. K., 1953: The formation of atmospheric ice crystals by the freezing of droplets. Quart. J. Roy. Meteor. Soc., 79, 510-519, https://doi.org/10.1002/qj.49707934207.

Blahak, U., 2007: Radar_mie_lm and radar_mielib_Calculation of radar reflectivity from model output. Tech. Rep., Institute for Meteorology and Climate Research, University Research Center, Karlsruhe, Germany, 150 pp.

Bluestein, H. B., and M. L. Weisman, 2000: The interaction of numerically simulated supercells initiated along lines. Mon. Wea. Rev., 128, 3128-3149, https://doi.org/10.1175/1520-0493(2000) $128<3128$ :TIONSS $>2.0 . \mathrm{CO} ; 2$

Braun, S. A., and R. A. Houze, 1994: The transition zone and secondary maximum of radar reflectivity behind a midlatitude squall line: Results retrieved from Doppler radar data. J. Atmos. Sci., 51, 2733-2755, https://doi.org/10.1175/1520-0469(1994) 051<2733:TTZASM>2.0.CO;2.

, and - 1995: Melting and freezing in a mesoscale convective system. Quart. J. Roy. Meteor. Soc., 121, 55-77, https:// doi.org/10.1002/qj.49712152104.

Castellano, N. E., C. M. Scavuzzo, B. Nasello, G. M. Caranti, and L. Levin, 1994: A comparative study on hailstone trajectories using different motion equations, drag coefficients and wind fields. Atmos. Res., 33, 309-331, https://doi.org/10.1016/01698095(94)90025-6.

Chen, S., and W. R. Cotton, 1988: The sensitivity of a simulated extratropical mesoscale convective system to longwave radiation and ice-phase microphysics. J. Atmos. Sci., 45, 3897-3910, https://doi.org/10.1175/1520-0469(1988)045<3897:TSOASE> 2.0.CO;2.

Cholette, M., H. Morrison, J. A. Milbrandt, and J. M. Thériault, 2019: Parameterization of the bulk liquid fraction on mixedphase particles in the Predicted Particle Properties (P3) scheme: Description and idealized simulations. J. Atmos. Sci., 76, 561-582, https://doi.org/10.1175/JAS-D-18-0278.1.

Colle, B. A., B. F. Small, and M. Yang, 2002: Numerical simulations of a landfalling cold front observed during coast: Rapid evolution and responsible mechanisms. Mon. Wea. Rev., 130, 1945-1966, https://doi.org/10.1175/1520-0493(2002)130<1945: NSOALC $>2.0 . \mathrm{CO} ; 2$

, J. B. Wolfe, W. J. Steenburgh, D. E. Kingsmill, J. A. W. Cox, and J. C. Shafer, 2005: High-resolution simulations and microphysical validation of an orographic precipitation event over the Wasatch Mountains during IPEX IOP3. Mon. Wea. Rev., 133, 2947-2971, https://doi.org/10.1175/MWR3017.1.

Computational and Information Systems Laboratory, 2017: Cheyenne: HPE/SGI ICE XA System (Wyoming-NCAR Alliance). National Center for Atmospheric Research, Boulder, CO, https://doi.org/10.5065/D6RX99HX.

Corfidi, S. F., 2003: Cold pools and MCS propagation: Forecasting the motion of downwind-developing mcss. Wea. Forecasting, 18, 997-1017, https://doi.org/10.1175/1520-0434(2003)018<0997: CPAMPF $>2.0 . \mathrm{CO} ; 2$.

Davies-Jones, R., 1984: Streamwise vorticity: The origin of updraft rotation in supercell storms. J. Atmos. Sci., 41, 2991-3006, https:// doi.org/10.1175/1520-0469(1984)041<2991:SVTOOU>2.0.CO;2.

Dawson, D. T., M. Xue, J. A. Milbrandt, and M. K. Yau, 2010: Comparison of evaporation and cold pool development between single-moment and multimoment bulk microphysics schemes in idealized simulations of tornadic thunderstorms. Mon. Wea. Rev., 138, 1152-1171, https://doi.org/10.1175/2009MWR2956.1. 
Dennis, A. S., and D. J. Musil, 1973: Calculations of hailstone growth and trajectories in a simple cloud model. J. Atmos. Sci., 30, 278-288, https://doi.org/10.1175/1520-0469(1973)030<0278: COHGAT $>2.0 . \mathrm{CO} ; 2$.

Ekman, A. M. L., A. Engstrom, and A. Soderberg, 2011: Impact of two-way aerosol-cloud interaction and changes in aerosol size distribution on simulated aerosol-induced deep convective cloud sensitivity. J. Atmos. Sci., 68, 685-697, https://doi.org/10.1175/ 2010JAS3651.1.

Fan, J., and Coauthors, 2009: Dominant role by vertical wind shear in regulating aerosol effects on deep convective clouds. J. Geophys. Res., 114, D22206, https://doi.org/10.1029/2009JD012352.

_ L. R. Leung, D. Rosenfeld, Q. Chen, Z. Li, J. Zhang, and H. Yan, 2013: Microphysical effects determine macrophysical response for aerosol impacts on deep convective clouds. Proc. Natl. Acad. Sci., 110, E4581-E4590, https://doi.org/10.1073/ pnas.1316830110.

Ferrier, B. S., 1994: A double-moment multiple-phase four-class bulk ice scheme. Part I: Description. J. Atmos. Sci., 51, 249-280, https:// doi.org/10.1175/1520-0469(1994)051<0249:ADMMPF>2.0.CO;2.

Fovell, R. G., and Y. Ogura, 1988: Numerical simulation of a midlatitude squall line in two dimensions. J. Atmos. Sci., 45, 3846-3879, https://doi.org/10.1175/1520-0469(1988)045<3846: NSOAMS $>2.0 . \mathrm{CO} ; 2$.

French, M. M., P. S. Skinner, L. J. Wicker, and H. B. Bluestein, 2015: Documenting a rare tornado merger observed in the 24 May 2011 El Reno-Piedmont, Oklahoma, supercell. Mon. Wea. Rev., 143, 3025-3043, https://doi.org/10.1175/MWR-D14-00349.1.

Grabowski, W. W., 2003: Impact of cloud microphysics on convective-radiative quasi equilibrium revealed by cloudresolving convection parameterization. J. Climate, 16, 3463-3475, https://doi.org/10.1175/1520-0442(2003)016<3463:IOCMOC> 2.0.CO;2.

- 2006: Indirect impact of atmospheric aerosol in idealized simulations of convective-radiative quasi equilibrium. J. Climate, 19, 4664-4682, https://doi.org/10.1175/JCLI3857.1.

— deep convection applying a novel modeling methodology. Part II: Double-moment microphysics. J. Atmos. Sci., 73, 37493770, https://doi.org/10.1175/JAS-D-15-0367.1.

Hallett, J., and S. C. Mossop, 1974: Production of secondary ice particles during the riming process. Nature, 249, 26-28, https:// doi.org/10.1038/249026a0.

Heiblum, R. H., I. Koren, and O. Altaratz, 2012: New evidence of cloud invigoration from TRMM measurements of rain center of gravity. Geophys. Res. Lett., 39, L08803 https://doi.org/ 10.1029/2012GL051158.

Houze, R. A., W. Schmid, R. G. Fovell, and H.-H. Schiesser, 1993: Hailstorms in Switzerland: Left movers, right movers, and false hooks. Mon. Wea. Rev., 121, 3345-3370, https://doi.org/ 10.1175/1520-0493(1993)121<3345:HISLMR > 2.0.CO;2.

Ivanova, I. T., and H. G. Leighton, 2008: Aerosol-cloud interactions in a mesoscale model. Part I: Sensitivity to activation and collision-coalescence. J. Atmos. Sci., 65, 289-308, https:// doi.org/10.1175/2007JAS2207.1.

Jensen, A. A., J. Y. Harringtong, and H. Morrison, 2018: Microphysical characteristics of squall-line stratiform precipitation and transition zones simulated using an ice particle propertyevolving model. Mon. Wea. Rev., 146, 723-743, https://doi.org/ 10.1175/MWR-D-17-0215.1.

Jensen, M. P., and Coauthors, 2016: The Midlatitude Continental Convective Clouds Experiment (MC3E). Bull. Amer.
Meteor. Soc., 97, 1667-1686, https://doi.org/10.1175/BAMSD-14-00228.1.

Kain, J. S., and Coauthors, 2008: Some practical considerations regarding horizontal resolution in the first generation of operational convection-allowing NWP. Wea. Forecasting, 23, 931-952, https://doi.org/10.1175/WAF2007106.1.

Kamra, A. K., R. V. Bhalwankar, and A. B. Sathe, 1991: Spontaneous breakup of charged and uncharged water drops freely suspended in a wind tunnel. J. Geophys. Res., 96, 1715917 168, https://doi.org/10.1029/91JD01475.

Khain, A., A. Pokrovsky, M. Pinsky, A. Seifert, and V. Phillips, 2004: Simulation of effects of atmospheric aerosols on deep turbulent convective clouds using a spectral microphysics mixed-phase cumulus cloud model. Part I: Model description and possible applications. J. Atmos. Sci., 61, 2963-2982, https:// doi.org/10.1175/JAS-3350.1.

Knight, C. A., D. H. Ehhalt, N. Roper, and N. C. Knight, 1975: Radial and tangential variation of deuterium in hailstones. J. Atmos. Sci., 32, 1990-2000, https://doi.org/10.1175/15200469(1975)032<1990:RATVOD > 2.0.CO;2.

Koren, I., J. V. Martins, L. A. Remer, and H. Afargan, 2008: Smoke invigoration versus inhibition of clouds over the Amazon. Science, 321, 946-949, https://doi.org/10.1126/science.1159185.

- L. A. Remer, O. Altaratz, J. V. Martins, and A. Davidi, 2010: Aerosol-induced changes of convective cloud anvils produce climate warming. Atmos. Chem. Phys., 10, 5001-5010, https:// doi.org/10.5194/acp-10-5001-2010.

Kumjian, M. R., Z. J. Lebo, and H. C. Morrison, 2015: On the mechanisms of rain formation in an idealized supercell storm. Mon. Wea. Rev., 143, 2754-2773, https://doi.org/10.1175/MWRD-14-00402.1.

Leary, C. A., and R. A. Houze, 1979: Melting and evaporation pf hydrometeors in precipitation from the anvil clouds of deep tropical convection. J. Atmos. Sci., 36, 665-679, https://doi.org/ 10.1175/1520-0469(1979)036<0669:MAEOHI >2.0.CO;2.

Lebo, Z. J., 2014: The sensitivity of a numerically simulated idealized squall line to the vertical distribution of aerosols. J. Atmos. Sci., 71, 4581-4596, https://doi.org/10.1175/JAS-D14-0068.1.

_ 2018: A numerical investigation of the potential effects of aerosol-induced warming and updraft width and slope on updraft intensity in deep convective clouds. J. Atmos. Sci., $\mathbf{7 5}$, 535-554, https://doi.org/10.1175/JAS-D-16-0368.1.

— vigoration due to increased aerosol concentration. Atmos. Chem. Phys., 11, 5407-5429, https://doi.org/10.5194/acp-115407-2011.

— turbations on simulated idealized squall lines. Mon. Wea. Rev., 142, 991-1009, https://doi.org/10.1175/MWR-D-13-00156.1.

,-- , and J. H. Seinfeld, 2012: Are simulated aerosol-induced effects on deep convective clouds strongly dependent on saturation adjustment? Atmos. Chem. Phys., 12, 9941-9964, https:// doi.org/10.5194/acp-12-9941-2012.

Lee, S. S., L. J. Donner, V. T. J. Phillips, and Y. Ming, 2008: Examination of aerosol effects on precipitation in deep convective clouds during the 1997 ARM summer experiment. Quart. J. Roy. Meteor. Soc., 134, 1201-1220, https://doi.org/10.1002/ qj.287.

Li, Z., F. Niu, J. Fan, Y. Liu, D. Rosenfeld, and Y. Ding, 2011: Long-term impacts of aerosols on the vertical development of clouds and precipitation. Nat. Geosci., 4, 888-894, https:// doi.org/10.1038/ngeo1313. 
Loftus, A. M., W. R. Cotton, and G. G. Carrio, 2014: A triplemoment hail bulk microphysics scheme. Part I: Description and initial evaluation. Atmos. Res., 149, 35-57, https://doi.org/ 10.1016/j.atmosres.2014.05.013.

Lynn, B. H., A. P. Khain, J. Dudhia, D. Rosenfeld, A. Pokrovsky, and A. Seifert, 2005: Spectral (bin) microphysics coupled with a mesoscale model (MM5). Part I: Model description and first results. Mon. Wea. Rev., 133, 44-58, https://doi.org/10.1175/ MWR-2840.1.

Mansell, E. R., and C. L. Ziegler, 2013: Aerosol effects on simulated storm electrification and precipitation in a two-moment bulk microphysics model. J. Atmos. Sci., 70, 2032-2050, https:// doi.org/10.1175/JAS-D-12-0264.1.

Markowski, P., and Y. Richardson, 2010: Mesoscale Meteorology in Midlatitudes. Wiley, $430 \mathrm{pp}$.

Marwitz, J. D., 1987: Deep orographic storms over the Sierra Nevada. Part I: Thermodynamic and kinematic structure. J. Atmos. Sci., 44, 159-173, https://doi.org/10.1175/1520-0469(1987)044<0159: DOSOTS $>2.0$.CO;2.

Meyers, M. P., P. J. DeMott, and W. R. Cotton, 1992: New primary ice nucleation parameterization in an explicit model. J. Appl. Meteor., 31, 708-721, https://doi.org/10.1175/1520-0450(1992) 031<0708:NPINPI > 2.0.CO;2.

Milbrandt, J. A., and M. K. Yau, 2005: A multimoment bulk microphysics parameterization. Part I: Analysis of the role of the spectral shape parameter. J. Atmos. Sci., 62, 3051-3064, https://doi.org/10.1175/JAS3534.1.

Mitra, S. K., O. Vohl, M. Ahr, and H. R. Pruppacher, 1990: A wind tunnel and theoretical study of the melting behavior of atmospheric ice particles. Part IV: Experiment and theory for snowflakes. J. Atmos. Sci., 47, 584-591, https://doi.org/10.1175/ 1520-0469(1990)047<0584:AWTATS >2.0.CO;2.

Morrison, H., 2016: Impacts of updraft size and dimensionality on the perturbation pressure and vertical velocity in cumulus convection. Part II: Simple, generalized analytic solutions. J. Atmos. Sci., 73, 1441-1454, https://doi.org/10.1175/JAS-D15-0040.1.

, and J. Milbrandt, 2011: Comparison of two-moment bulk microphysics schemes in idealized supercell thunderstorm simulations. Mon. Wea. Rev., 139, 1103-1130, https://doi.org/10.1175/ 2010MWR3433.1.

_ G. Thompson, and V. Tatarskii, 2009: Impact of cloud microphysics on the development of trailing stratiform precipitation in a simulated squall line: Comparison of one- and two-moment schemes. Mon. Wea. Rev., 137, 991-1007, https://doi.org/ 10.1175/2008MWR2556.1.

_ - S. A. Tessendorf, K. Ikeda, and G. Thompson, 2012: Sensitivity of a simulated midlatitude squall line to parameterization of raindrop breakup. Mon. Wea. Rev., 140, 2437-2460, https://doi.org/10.1175/MWR-D-11-00283.1.

Nelson, S. P., 1983: The influence of storm flow structure on hail growth. J. Atmos. Sci., 40, 1965-1983, https://doi.org/10.1175/ 1520-0469(1983)040<1965:TIOSFS $>2.0$. CO;2.

Orf, L., R. Wilhelmson, B. Lee, C. Finley, and A. Houston, 2017: Evolution of a long-track violent tornado within a simulated supercell. Bull. Amer. Meteor. Soc., 98, 45-68, https://doi.org/ 10.1175/BAMS-D-15-00073.1.

Orville, H. D., R. D. Farley, Y. Chi, and F. J. Kopp, 1989: The primary cloud physics mechanisms of microburst formation. Atmos. Res., 24, 343-357, https://doi.org/10.1016/0169-8095(89)90054-9.

Parker, M. D., 2010: Relationship between system slope and updraft intensity in squall lines. Mon. Wea. Rev., 138, 3572-3578, https://doi.org/10.1175/2010MWR3441.1.
Pazmany, A. L., J. B. Mead, H. B. Bluestein, J. C. Snyder, and J. B. Houser, 2013: A mobile Rapid-Scanning X-band Polarimetric (RaXPol) Doppler radar system. J. Atmos. Oceanic Technol., 30, 1398-1413, https://doi.org/10.1175/JTECH-D-12-00166.1.

Phillips, V. T. J., and L. J. Donner, 2006: Cloud microphysics, radiation and vertical velocities in two- and three-dimensional simulations of deep convection. Quart. J. Roy. Meteor. Soc., 132, 3011-3033, https://doi.org/10.1256/qj.05.171.

- A. Pokrovsky, and A. Khain, 2007: The influence of timedependent melting on the dynamics and precipitation production in maritime and continental storm clouds. J. Atmos. Sci., 64, 338-359, https://doi.org/10.1175/JAS3832.1.

Pruppacher, H. R., and J. D. Klett, 1997: Microphysics of Clouds and Precipitation. 2nd ed. Springer, 954 pp.

Rasmussen, R. M., and A. J. Heymsfield, 1987a: Melting and shedding of graupel and hail. Part I: Model physics. J. Atmos. Sci., 44, 2754-2763, https://doi.org/10.1175/1520-0469(1987)044<2754: MASOGA $>2.0 . \mathrm{CO} ; 2$.

— and _ 1987b: Melting and shedding of graupel and hail. Part III: Investigation of the role of shed drops as hail embryos in the 1 August CCOPE severe storm. J. Atmos. Sci., 44, 2783-2803, https://doi.org/10.1175/1520-0469(1987)044<2783:MASOGA> 2.0.CO;2.

— V. Vevizzani, and H. R. Pruppacher, 1984: A wind tunnel and theoretical study on the melting behavior of atmospheric ice particles. III: Experiment and theory for spherical ice particles of radius $>500 \mu \mathrm{m}$. J. Atmos. Sci., 41, 381-388, https://doi.org/10.1175/1520-0469(1984)041<0381:AWTATS> 2.0.CO;2

Reisin, T., Z. Levin, and S. Tzivion, 1996: Rain production in convective clouds as simulated in an axisymmetric model with detailed microphysics. Part I: Description of the model. J. Atmos. Sci., 53, 497-519, https://doi.org/10.1175/ 1520-0469(1996)053<0497:RPICCA > 2.0.CO;2.

Rosenfeld, D., and W. L. Woodley, 2000: Deep convective clouds with sustained supercooled liquid water down to $-37.5^{\circ} \mathrm{C}$. Nature, 405, 440-442, https://doi.org/10.1038/35013030.

, U. Lohmann, G. B. Raga, C. D. O’Dowd, M. Kulmala, S. Fuzzi, A. Reissel, and M. O. Andreae, 2008: Flood or drought: How do aerosols affect precipitation. Science, 321, 1309-1313, https:// doi.org/10.1126/science.1160606.

Rotunno, R., J. B. Klemp, and M. L. Weisman, 1988: A theory for strong, long-lived squall lines. J. Atmos. Sci., 45, 463-485, https://doi.org/10.1175/1520-0469(1988)045<0463:ATFSLL> 2.0.CO;2.

Sarkadi, N., I. Geresdi, and G. Thompson, 2016: Numerical simulation of precipitation formation in the case orographically induced convective cloud: Comparison of the results of bin and bulk microphysical schemes. Atmos. Res., 180, 241-261, https://doi.org/10.1016/j.atmosres.2016.04.010.

Schlesinger, R. E., 1984: Effects of the pressure perturbation field in numerical models of unidirectionally sheared thunderstorm convection: Two versus three dimensions. J. Atmos. Sci., 41, 1571-1587, https://doi.org/10.1175/1520-0469(1984)041<1571: EOTPPF $>2.0 . \mathrm{CO} ; 2$.

Seifert, A., and K. D. Beheng, 2006: A two-moment cloud microphysics parameterization for mixed-phase clouds. Part 2: Maritime vs. continental deep convective storms. Meteor. Atmos. Phys., 92, 67-82, https://doi.org/10.1007/s00703-005-0113-3.

, C. Köhler, and K. D. Beheng, 2012: Aerosol-cloudprecipitation effects over Germany as simulated by a convectivescale numerical weather prediction model. Atmos. Chem. Phys., 12, 709-725, https://doi.org/10.5194/acp-12-709-2012. 
Seigel, R. B., S. C. van den Heever, and S. Saleeby, 2013: Mineral dust indirect effects and cloud radiative feedbacks of a simulated idealized nocturnal squall line. Atmos. Chem. Phys., 13, 4467-4485, https://doi.org/10.5194/acp-13-4467-2013.

Smith, P. L., 1984: Equivalent radar reflectivity factors for snow and ice particles. J. Climate Appl. Meteor., 23, 1258-1260, https://doi.org/10.1175/1520-0450(1984)023<1258:ERRFFS> 2.0.CO;2.

Straka, J., 2009: Cloud and Precipitation Microphysics: Principles and Parameterizations. Cambridge University Press, $406 \mathrm{pp}$. , and J. R. Anderson, 1993: Numerical simulations of microburstproducing storms: Some results from storms observed during COHMEX. J. Atmos. Sci., 50, 1329-1348, https://doi.org/ 10.1175/1520-0469(1993)050<1329:NSOMPS $>2.0 . \mathrm{CO} ; 2$.

Tanamachi, R. L., P. L. Heinselman, and L. J. Wicker, 2015: Impacts of a storm merger on the 24 May 2011 El Reno, Oklahoma, tornadic supercell. Wea. Forecasting, 30, 501-502, https://doi.org/ 10.1175/WAF-D-14-00164.1.

Tao, W.-K., J. Simpson, S. Lang, M. McCumber, R. Adler, and R. Penc, 1990: An algorithm to estimate the heating budget from vertical hydrometeor profiles. J. Appl. Meteor., 29, 1232-1244, https://doi.org/10.1175/1520-0450(1990)029<1232: AATETH $>2.0 . \mathrm{CO} ; 2$.

_ J. R. Scala, B. Ferrier, and J. Simpson, 1995: The effect of melting processes on the development of a tropical and midlatitude squall line. J. Atmos. Sci., 52, 1934-1948, https://doi.org/ 10.1175/1520-0469(1995)052<1934:TEOMPO >2.0.CO;2.

__ X. Li, A. Khain, T. Matsui, S. Lang, and J. Simpson, 2007: Role of atmospheric aerosol concentration on deep convective precipitation: Cloud-resolving model simulations. J. Geophys. Res., 112, D24S18, https://doi.org/10.1029/2007JD008728.

Tzivion, S., G. Feingold, and Z. Levin, 1987: An efficient numerical solution to the stochastic collection equation. J. Atmos. Sci., 44, 3139-3149, https://doi.org/10.1175/1520-0469(1987)044<3139: AENSTT $>2.0 . \mathrm{CO} ; 2$.

,-- , and -1989 : The evolution of raindrop spectra. Part II: Collisional collection/breakup and evaporation in a rainshaft. J. Atmos. Sci., 46, 3312-3327, https://doi.org/10.1175/ 1520-0469(1989)046<3312:TEORSP $>2.0$.CO;2.

Vali, G., 1975: Remarks on the mechanism of atmospheric ice nucleation. Proc. Eighth Int. Conf. on Nucleation, St. Petersburg, Russia, 265-269.
Van den Heever, S. C., G. G. Carrio, W. R. Cotton, P. J. DeMott, and A. J. Prenni, 2006: Impacts of nucleating aerosol on Florida storms. Part I: Mesoscale simulations. J. Atmos. Sci., 63, 1752-1775, https://doi.org/10.1175/JAS3713.1.

Van Weverberg, K., A. M. Vogelmann, H. Morrison, and J. A. Milbrandt, 2012: Sensitivity of idealized squall-line simulations to the level of complexity used in two-moment bulk microphysics schemes. Mon. Wea. Rev., 140, 1883-1907, https://doi.org/ 10.1175/MWR-D-11-00120.1.

Walko, R. L., W. R. Cotton, M. P. Meyers, and J. Y. Harrington, 1995: New RAMS cloud microphysics parameterization. Part I: The single-moment scheme. Atmos. Res., 38, 29-62, https:// doi.org/10.1016/0169-8095(94)00087-T.

Weisman, M. L., and R. Rotunno, 2000: The use of vertical wind shear versus helicity in interpreting supercell dynamics. J. Atmos. Sci., 57, 1452-1472, https://doi.org/10.1175/1520-0469(2000)057<1452: TUOVWS $>2.0$. CO;2.

—, W. C. Skamarock, and J. B. Klemp, 1997: The resolution dependence of explicitly modeled convective systems. Mon. Wea. Rev., 125, 527-548, https://doi.org/10.1175/1520-0493(1997) 125<0527:TRDOEM > 2.0.CO;2.

Wilhelmson, R., 1974: The life cycle of a thunderstorm in three dimensions. J. Atmos. Sci., 31, 1629-1651, https://doi.org/ 10.1175/1520-0469(1974)031<1629:TLCOAT>2.0.CO;2.

Wu, D., X. Dong, B. Xi, Z. Feng, A. Kennedy, G. Mullendore, M. Gilmore, and W. Tao, 2013: Impacts of microphysical scheme on convective and stratiform characteristics in two high precipitation squall line events. J. Geophys. Res., 118, 11119-11 135, https://doi.org/10.1002/jgrd.50798.

Wu, W., and G. M. McFarquhar, 2016: On the impacts of different definitions of maximum dimension for nonspherical particles recorded by 2D imaging probes. J. Atmos. Oceanic Technol., 33, 1057-1072, https://doi.org/10.1175/JTECH-D-15-0177.1.

Xue, L., and Coauthors, 2017: Idealized simulations of a squall line from the MC3E field campaign applying three bin microphysics schemes: Dynamic and thermodynamic structure. Mon. Wea. Rev., 145, 4789-4812, https://doi.org/10.1175/MWRD-16-0385.1.

Yuan, T., L. Remer, K. E. Pickering, and H. Yu, 2011: Observational evidence of aerosol enhancement of lightning activity and convective invigoration. Geophys. Res. Lett., 38, L04701, https://doi.org/10.1029/2010GL046052. 